Final Report for Grant No. DE-FG02-05ER15648 6/15/05-6/14/08.

\title{
"Role of a Transcriptional Regulator in Programmed Cell Death and Plant Development"
}

\section{PI: Julie M. Stone}

Recipient organization: University of Nebraska-Lincoln

312 N. 14th Street

Alexander West

Lincoln, NE 68588-0430

Telephone: (402) 472-3171

Fax: (402) 472-3834

\section{Summary of outcomes:}

Our initial manuscript describing the fbr6 mutant was published in 2005.

Julie M. Stone, Xinwen Liang, Emily R. Nekl and Justin J. Stiers (2005) Arabidopsis AtSPL14, a plant-specific SBP-domain transcription factor, participates in plant development and sensitivity to fumonisin B1. The Plant Journal 41:744-754.

Other manuscripts directly based on the funded project include:

Xinwen Liang, Tara Nazarenus and Julie M. Stone (2008) Identification of a consensus DNA binding site for the Arabidopsis SBP domain transcription factor, AtSPL14, and binding kinetics by surface plasmon resonance. Biochemistry 47: 3645-3653.

Jiusheng Lin, S. Madhavan and Julie M. Stone (2008) Arabidopsis AtSPL14, an SBP domain transcription factor, influences photosynthesis and water use efficiency in the fumonisin b1resistant fbr6 mutant (submitted).

Jiusheng Lin, Jonathan Markham and Julie M. Stone (2008) Genetic interaction between FUMONISIN B1-RESISTANT6 (FBR6) and ACCELERATED CELL DEATH5 (ACD5) in sphingolipid-mediated modulation of Arabidopsis thaliana programmed cell death (in preparation).

Additional manuscripts closely related to the proposed work include:

Tsanko Gechev, Frank Van Breusegem, Julie M. Stone, Ilya Denev and Christophe Laloi (2006) Reactive oxygen species as signals controlling plant stress responses and programmed cell death. Bioessays 28: 1091-1101 (Invited and peer-reviewed).

Laurence V. Bindschedler, Julia Dewdney, Kris A. Blee, Julie M. Stone, Tsuneaki Asai, Julia Plotnikov, Carine Denoux, Tezni Hayes, Chris Gerrish, Dewi R. Davies, Frederick M. Ausubel, and G. Paul Bolwell (2006) Peroxidase-dependent apoplastic oxidative burst in Arabidopsis required for pathogen resistance. The Plant Journal 47:851-863.

Sadaf Khan and Julie M. Stone (2007) Addendum: A possible role for Arabidopsis thaliana GH3.9 in auxin and jasmonate cross talk to influence root development. Plant Signaling \& Behavior 2: 483485.

Sadaf Khan and Julie M. Stone (2007) Arabidopsis thaliana GH3.9 influences primary root growth. Planta 226: 21-34.

Julie M. Stone and Mark A. Wilson (2007) Other antioxidants. In Redox Biochemistry, R. Banerjee, ed., John Wiley \& Sons, Inc., New York, NY. p. 27-35.

Sadaf Khan and Julie M. Stone (2008) Molecular basis of the dominant Arabidopsis thaliana $D$-fbr7 fumonisin B1-resistant mutant. (manuscript under revision).

Ilya Gadjev, Julie M. Stone and Tsanko S. Gechev (2008) Programmed cell death in plants: new insights into redox regulation and the role of hydrogen peroxide. International Review of Cell and Molecular Biology (formerly International Review of Cytology - a Survey of Cell Biology) 270:87143 (Invited and peer-reviewed). 


\section{Objectives, Experimental Plan, and Outcomes}

Project DE-FG02-05ER15648, "Role of a Transcriptional Regulator in Programmed Cell Death and Plant Development", was funded by the Department of Energy from June 2005 to June 2008 at a total cost of $\$ 354,000$. The long-term goal of the Stone lab research is to understand the role(s) and molecular mechanisms of programmed cell death (PCD) in the controlling plant growth, development and responses to biotic and abiotic stress. We developed a genetic selection scheme to identify $A$. thaliana FB1-resistant ( $f b r$ ) mutants as a way to find genes involved in PCD (Stone et al., 2000; Stone et al., 2005; Khan and Stone, 2008). The disrupted gene in fbr6 (AtSPL14) responsible for the FB1insensitivity and plant architecture phenotypes encodes a plant-specific SBP DNA-binding domain transcriptional regulator (Stone et al., 2005; Liang et al., 2008).

This research plan is designed to fill gaps in the knowledge about the role of SPL14 in plant growth and development. The work is being guided by three objectives aimed at determining the pathways in which SPL14 functions to modulate PCD and/or plant development:

1) determine how $S P L 14$ functions in plant development,

2) identify target genes that are directly regulated by SPL14, and

3) identify SPL14 modifications and interacting proteins.

We made significant progress during the funding period. Briefly, some major accomplishments are highlighted below:

- To identify potential AtSPL14 target genes, we identified a consensus DNA binding site for the AtSPL14 SBP DNA-binding domain using systematic evolution of ligands by exponential selection (SELEX) and site-directed mutagenesis (Liang et al., 2008). This consensus binding site was used to analyze Affymetrix microarray gene expression data obtained from wild-type and fbr6 mutant plants to find possible AtSPL14-regulated genes. These candidate AtSPL14-regulated genes are providing new information on the molecular mechanisms linking plant PCD and plant development through modulation of the $26 \mathrm{~S}$ proteasome.

- Transgenic plants expressing epitope-tagged versions of AtSPL14 are being used to confirm the AtSPL14 targets (by ChIP-PCR) and further dissect the molecular interactions (Nazarenus, Liang and Stone, in preparation)

- Double mutants generated between fbr6 and various accelerated cell death (acd) mutants indicate that sphingolipid metabolism is influenced by AtSPL14 and sphingolipidomics profiling supports this conclusion (Lin, Markham and Stone, in preparation).

- A new set of phenotypes have been uncovered in the original fbr6-1 mutant, including a short-root phenotype related to auxin signaling and altered photosynthetic parameters related to stomatal density and conductance (Lin and Stone, in preparation; Lin, Madhavan and Stone, in preparation). Additional AtSPL14-related mutants and transgenic plants have been generated to effectively dissect the functions of AtSPL14, including a dominant negative fbr6-2 allele and transgenic plants overexpressing FBR6/AtSPL14 that display an accelerated cell death (acd) phenotype.

\section{Objective \#1) Determine how SPL14 functions in plant development and PCD}

The working hypothesis for Objective \#1 is that the function of SPL14 in plants is related to one or more of the pathways influenced by FB1: cell death, sphingolipid signaling, phase transitions, light perception/signaling, and hormone signaling.

\section{Cell death-related double mutants and phenotypic analyses}

Selected lesion mimic mutants that spontaneously form lesions in the absence of pathogen infection (accelerated cell death, acd, proposed to act in opposition to fbr6 in regulating PCD) were chosen with the hypothesis that the double mutants might regain sensitivity to FB1 and/or suppress spontaneous cell death. We have been unable to recover fbr6 acd11 mutants, but we successfully generated double mutants between $\mathrm{fbr} 6$ and $a c d 1$, acd2 and acd5 (single mutants obtained from Jean Greenberg, U. of Chicago). These double mutants, the single mutants, and wild-type controls were 
tested for FB1 sensitivity using our fbr phenotype assay (ability to develop when sown on FB1containing agar plates) and systemic FB1-resistance assay, leaf infiltration followed by monitoring systemic cell death at distal leaves (systemic assay, sys-r). At the germination/development stage we found that fbr6 suppresses the enhanced sensitivity of acd5, but not acd1 nor acd2 (data not shown). In the systemic assay, we found that the fbr6 mutant was clearly resistant to systemic cell death (sysr). Similar to the results obtained in the fbr plate assay, the fbr6 acd 1 and fbr 6 acd 2 double mutants were supersensitive to systemic cell death (sys-s). However, the fbr6 acd5 mutant was as resistant to systemic cell death as the fbr6 mutant alone (sys-r). That is, the fbr6 mutation effectively and fully suppressed the acd5 cell death phenotype using this assay (Figure 1).

Figure 1. FB1-induced systemic cell death (sys-r/sys-s) in fbr6 acdx double mutants. Relevant

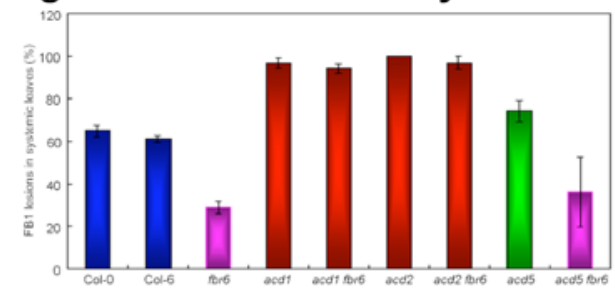
genotypes were subjected to the FB1-resistance systemic assay. Fifty plants of each genotype were assayed in four independent experiments, and the proportion of plants showing systemic cell death was determined. Different colors indicate significantly different values $(\mathrm{P}<0.05)$. Nearly $100 \%$ of acd 1 , acd2, acd $1 \mathrm{fbr} 6$ and acd 2 fbr6 mutants were sys-s, while fbr6 was sys-r with less than $30 \%$ of plants displaying systemic lesions. acd5 was more sensitive than wild-type plants, and the percentage of acd5 fbr6 sys-s plants was significantly less than that of acd5 or wild type and not significantly different from fbr6 (sys-r).

We also noted genotype differences in production of reactive oxygen species (ROS) and expression of some FB1-induced genes. ROS accumulation was determined by histochemical staining with nitroblue tetrazolium (NBT) or 3,3'-diaminobenzidine (DAB) to detect $\mathrm{O}_{2}{ }^{-}$or $\mathrm{H}_{2} \mathrm{O}_{2}$, respectively. Four-week-old plants of the relevant genotypes were mock-treated or FB1-treated by infiltrating a single lower leaf. Systemic leaves were stained after 5 days. In mock-treated plants, faint NBT or DAB precipitation was detected for WT, fbr6, acd $1 \mathrm{fbr} 6$, acd5 and acd5 fbr6, whereas stronger NBT or DAB precipitation was seen in acd1, acd2 and acd2 fbr6 leaves, indicating that introducing the fbr6 mutant to acd1 could reduce the $\mathrm{O}_{2}{ }^{-*}$ and $\mathrm{H}_{2} \mathrm{O}_{2}$ levels in the double mutant, but the $\mathrm{O}_{2}{ }^{--}$and $\mathrm{H}_{2} \mathrm{O}_{2}$ levels in acd2 fbr6 were no different from acd2. NBT and DAB staining was stronger for all the genotypes after FB1 infiltration. $\mathrm{O}_{2}{ }^{--}$and $\mathrm{H}_{2} \mathrm{O}_{2}$ levels in fbr6 were lower than those in wild type, and there was no difference in $\mathrm{O}_{2}{ }^{-}$and $\mathrm{H}_{2} \mathrm{O}_{2}$ levels between acd1 and acd $1 \mathrm{fbr} 6$ or between acd2 and acd2 fbr6. $\mathrm{O}_{2}{ }^{*-}$ and $\mathrm{H}_{2} \mathrm{O}_{2}$ levels were significantly lower in acd5 fbr6 than in acd5. Therefore, the fbr6 mutation could effectively suppress ROS accumulation in the acd5 mutant. For molecular markers, we examined expression of PATHOGENESIS-RELATED1 (PR1), a vacuolar processing enzyme ( $g V P E)$ and a gene encoding a sphingosine-1-phosphate lyase (DPL1) for steady-state transcript levels with and without FB1 treatment (Stone et al., 2000; Shimada et al., 2003; Kuroyanagi et al., 2005; Niu et al., 2007; Tsegaye et al., 2007). PR1 gene expression levels didn't correlate with FB1 sensitivity (data not shown), whereas the fbr6 mutation suppressed accumulation of the other two markers in acd5 (Figure 2).

Figure 2. Semi-quantitative RT-PCR analyses of (A) Vacuolar processing enzyme (gVPE)and
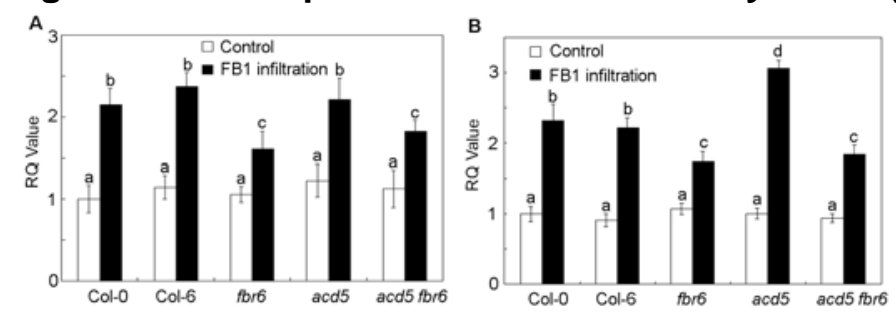
(B) Sphingoid Long Chain Base-Phosphate Lyase (DPL1) steady-state transcript levels. Total RNA was isolated from rosette leaves 5 days after FB1 treatment, reverse transcribed with oligo-dT, and used as a template for PCR with ACTIN2-, DPL1-, and gVPE-specific oligonucleotide primers to determine transcript levels. Relative expression was determined as the ratio of DPL1 or gVPE to ACTIN2 (loading control). Different letters indicate significantly different values $(P<0.05)$. 
The different ability of fbr6 to suppress the cell death susceptibility (and other markers, such as ROS accumulation and FB1-induced gene expression) of these distinct lesion mimic mutants might be related to differences in tissue expression and/or the nature of the encoded proteins. Both ACD1 and ACD2 encode proteins implicated in controlling PCD-inducing chlorophyll breakdown products, whereas $A C D 5$ and $A C D 11$ encode proteins implicated in sphingolipid metabolism, a ceramide kinase and a sphingosine transfer protein, respectively (Greenberg et al., 2000; Mach et al., 2001; Brodersen et al., 2002; Liang et al., 2003; Pruzinska et al., 2003; Tanaka et al., 2003; Yang et al., 2004; Pruzinska et al., 2005; Yao and Greenberg, 2006). Thus, we conclude that the fbr6 mutation influences cell death pathways primarily through sphingolipid signaling, as opposed to inappropriate accumulation of chlorophyll breakdown products generated during photosynthesis. This conclusion is supported by our sphingolipidomics profiling data (Figure 3).

\section{Sphingolipidomics Profiling Reveals Dramatic Differences in the Response of fbr6-1 to FB1}

The ability of the fbr 6 mutation to suppress the acd phenotype in a mutant affected in a putative ceramide kinase, compelled us to determine sphingolipid profiles for wild-type and fbr6-1 mutant plants (+ and - FB1) in our systemic FB1-resistance (sys-r) assay by HPLC/MS at the Danforth Center, St. Louis, MO (Markham and Jaworski, 2007). With more than 200 different plant sphingolipid species differing in saturation, hydroxylation and head groups (Dunn et al., 2004; Markham et al., 2006), these analyses provide massive amounts of data representing a comprehensive snapshot of all major classes of sphingolipid species in the analyzed tissue, including ceramides, hydroxyceramides, glucosylceramides, glycosylinositolphosphoceramides, sphingoid long chain bases (LCBs) and their phosphorylated derivatives (LCB-Ps). Only the most relevant and interesting results are summarized briefly here. FB1 treatment clearly caused a shift in sphingolipids pools, as predicted given its function as a competitive inhibitor of ceramide synthase (sphinganine $\mathrm{N}$-acyl transferase, Figure 4). In wildtype plants there was a shift from very long chain fatty acids (VLCFAs; C20 to C26) to shorter chain C16 FAs, but this shift was circumvented by the fbr6 mutation. FB1 treatment also caused significant accumulation of saturated LCBs and LCB-Ps, d18:0, t18:0, d18:0-P and t18:0-P, while there was little effect on d18:1, t18:1 and t18:1-P accumulation. The fbr6 mutant, however, accumulated very different levels and types of LCBs and LCB-Ps (which Jonathan Markham described as "really extraordinary!"), where both of the unsaturated versions (d18:1 and t18:1) are hyper-elevated at the expense of the saturated versions (d18:0 and t18:0) relative to wild-type plants (Figure 6).

Interestingly, the LCB-Ps were reduced relative to wild type, which is not completely consistent with our simplified models for why fbr6 might suppress the acd5 (deficient in a putative ceramide kinase, CERK) cell death phenotype. However the in vivo substrate(s) for ACD5 are not yet known (Liang et al., 2003), and we should be able to reconcile this model with our pending sphingolipid profiling on both acd5 and the acd5 fbr6 double mutant. Sphingolipidomics profiling on wild-type plants and sphingolipid metabolism mutants have revealed an unsuspected complexity to plant sphingolipid metabolism/signaling (Liang et al., 2003; Dunn et al., 2004; Chen et al., 2006; Markham et al., 2006; Tsegaye et al., 2007; Dietrich et al., 2008). 

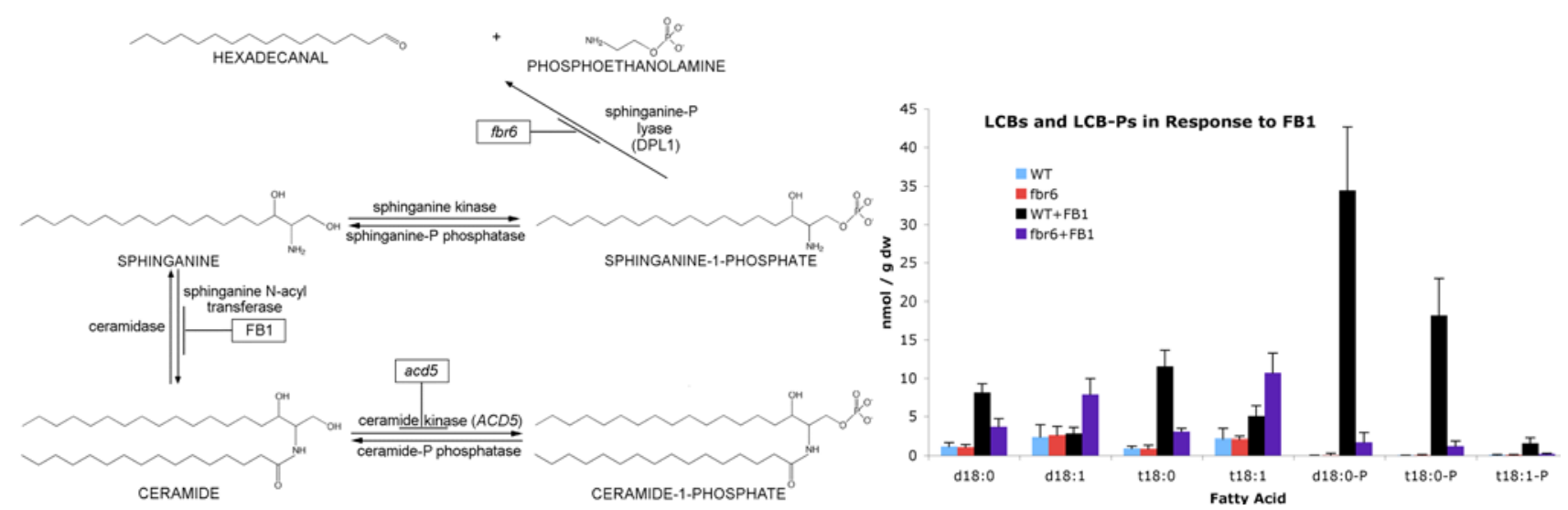

Figure 4. Generalized scheme of sphingolipid metabolism as it relates to acd5 fbr6 double mutant analyses and LCB accumulation in response to FB1. A) FB1 inhibits ceramide synthase (aka sphinganine $\mathrm{N}$-acyl transferase). Only a few of the well-studied key sphingolipid species in other eukaryotes (dihydro versions) most relevant to our acd5 fbr6 double mutant analyses are shown here. $A C D 5$ encodes a putative ceramide kinase, DPL1 encodes a sphinganine-P lyase that catalyzes an irreversible step in LCB-P catabolism. B) LCBs (e.g., sphinganine d18:0 and sphinganine-1-P d18:0P) differentially accumulate in $f b r 6$ and wild-type plants treated with FB1. Error bars represent standard deviation $(n=5)$.

\section{Objective \#2) Identify target genes that are directly regulated by SPL14}

The working hypothesis for Objective \#2 is that SPL14 binds to cis regulatory elements to regulate expression of genes that affect PCD and/or plant development.

\section{SPL14 target gene identification - SELEX and gene expression microarrays}

\section{SELEX (systematic evolution of ligands by exponential enrichment)}

Three complementary approaches were used to identify AtSPL14 target genes, WGPCR (whole genome PCR), SELEX (systematic evolution of ligands by exponential enrichment), and microarray gene expression analyses of wild-type and mutant plant tissues stimulated under specific conditions (Kehoe and Somerville, 1999; Schenk et al., 2000; Manuel et al., 2002; Wan et al., 2002; Kalifa et al., 2004; Ausubel et al., 2006). We used an affinity-based assay, referred to as SELEX or random binding site selection (RBSS), to screen a random pool of dsDNA fragments for sequences capable of binding to recombinant AtSPL14 protein to identify an AtSPL14-binding consensus DNA motif. Double-stranded DNA molecules containing a 26 nucleotide completely randomized central region were subjected to repetitive cycles of binding to recombinant AtSPL14 bound to a $\mathrm{Ni}^{2+}$-chelating affinity resin and PCR amplification. The individual binders were subsequently tested by electrophoretic mobility shift assays (EMSA) and competition with unlabeled probe, yielding twenty distinct dsDNA fragments. Alignment of the twenty individual binders using the web-based multiple expectation maximization for motif elicitation (MEME) analysis program (Grundy et al., 1997) yielded a consensus DNA binding motif (Figure 5). Mutational analyses indicated that predominantly the core motif, CGTAC, is essential for AtSPL14 protein binding to the DNA in vitro. In addition, we monitored the kinetic features of the AtSPL14 SBP domain binding to DNA by surface plasmon resonance (SPR) and compared and contrasted the target sequences we identified and the binding kinetics of AtSPL14 with those of other SBP domain proteins (Klein et al., 1996; Birkenbihl et al., 2005; Kropat et al., 2005). The representative Biochemistry Table of Contents Figure (Figure 5) represents the two $\mathrm{Zn}$ finger structure proposed for AtSPL14 and our identified consensus DNA binding motif (Liang et al., 2008). Using the relaxed consensus DNA-binding motif we identified for AtSPL14 (CGTAC), more than 6000 genes with the motif within 500 basepairs of the translation start site were found as possible AtSPL14 targets, and one gene of unknown function has sixteen occurrences. However, after 
analysis of microarray gene expression data comparing the transcriptomes of the $f b r 6$ mutant to wildtype plants (see below), a subset of these candidate target genes for AtSPL14 were identified by their altered expression in $\mathrm{fbr} 6$ mutants.

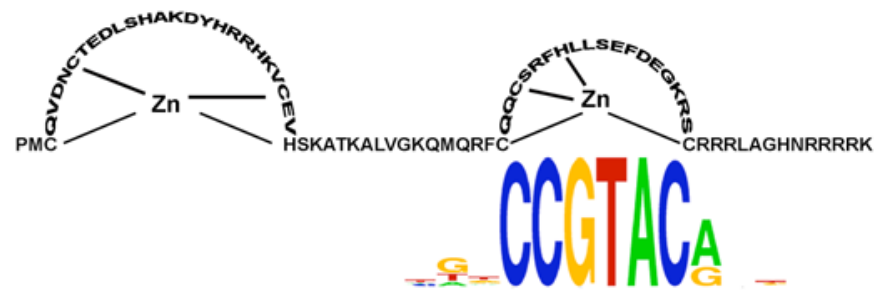

Figure 5. Representation of the AtSPL14 SBP binding domain. The presumed $\mathrm{Zn}^{2+}$ ion coordinating ligands and the consensus DNA binding motif identified by SELEX represented by WebLogo (Crooks et al., 2004) are shown (Liang et al., 2008).

\section{Microarray Gene Expression Analyses of the fbr6 Mutant Indicates AtSPL14 Might Function as a Repressor of Select Proteasome Subunit Genes}

To aid in determining FBR6/AtSPL14 target genes, the wild-type and fbr6 mutant transcriptomes were compared after mock treatment or imparting salicylic acid (SA)-induced oxidative stress using both slide-based 70-mer oligonucleotide arrays and Affymetrix ATH1 gene chips. Biological duplicates were performed with two genotypes (wild-type and fbr6 mutants) and two treatments (mock- and SA-treated). Specifically, 4 week-old plants were sprayed with either $0.1 \%$ Silwet (mock) or $1 \mathrm{mM} \mathrm{SA}$ in $0.1 \%$ Silwet (SA). Above ground tissues were harvested 8 hours after the treatment, flash frozen in liquid $\mathrm{N}_{2}$, total RNA was isolated using TRlzol according to manufacturer's instructions (Invitrogen, Carlsbad, CA, USA) and further purified using Qiagen RNAeasy Min Elute Cleanup kit (catalog \# 74204, Qiagen, Valencia, CA, USA). Fluorescent labeling with Cy5 and Cy3, hybridization to Affymetrix ATH1 24K arrays (which represent 24,000 genes), scanning, and data analysis were provided by UNL's Genomics Core Facility.

Using an average signal log ratio (SLR) cut-off of 0.5, we found that AtSPL14 expression was downregulated (an SLR of -0.85 in mock treated fbr6 mutant plants compared to wild type representing $\sim 50 \%$ of wild-type levels), consistent with our observations that the fbr6-1 allele is not a null mutant, but rather the T-DNA insertion in the 3'UTR results in reduced expression (Stone et al., 2005). When a more stringent SLR cut-off value was used (representing $>2$-fold difference), we found that the other genes downregulated in $f b r 6$ do not tend to cluster into major classes based on Gene Ontology (GO) designations with the majority having unknown functions. However, greater than half of the genes with known or predicted functions upregulated in $f b r 6$ are related to proteasomemediated protein degradation (16 of 32 genes in mock-treated samples and 27 of 48 genes in SAtreated samples), primarily encoding subunits of the 26S proteasome. Therefore, the most obvious global difference between the wild-type and fbr6 transcriptomes (in leaf tissue) appears to be proteasome-related genes. Does AtSPL14 normally function to repress a subset of proteasome subunit genes?

Protein degradation plays an important role in plant PCD (Kim et al., 2003; Hatsugai et al., 2004; Schaller, 2004; Hara-Nishimura et al., 2005; Kuroyanagi et al., 2005; Kim et al., 2006; Vacca et al., 2007). Proteasome-dependent protein degradation has been intimately linked to plant hormone signaling pathways, and subsequently cell differentiation, plant development and stress responses, (Moon et al., 2004; Smalle and Vierstra, 2004; Brukhin et al., 2005; Abas et al., 2006; Arnaud et al., 2006; Huang et al., 2006; Jin et al., 2006; Gusmaroli et al., 2007; Vacca et al., 2007; Kurepa et al., 2008; Staswick, 2008). Effects of the fbr6 mutation on expression of proteasome subunit genes could be due to direct regulation by FBR6/AtSPL14 or indirect regulation due to an overall physiological alterations due to the fbr 6 mutation. Indeed, many of the proteasome subunit genes appear to be coregulated based on publicly available microarray gene expression experiments (e.g., CressExpress, Genevestigator) (Zimmermann et al., 2004; Srinivasasainagendra et al., 2008).

Several of the $f b r 6$ upregulated genes, including the proteasome-related genes also possess the consensus DNA binding motif we identified by SELEX (CGTAC) within $1 \mathrm{~kb}$ of the annotated 
translation start sites. Promoters for twenty of the altered genes predicted to have the binding motif were amplified by PCR and tested for in vitro binding using EMSA as described (Liang et al., 2008). We have also confirmed the microarray results for selected genes by semi-quantitative RT-PCR (Figure 6), and are attempting to use chromatin immunoprecipitation (ChIP) assays in transgenic lines expressing epitope-tagged versions of AtSPL14 to determine whether AtSPL14 binds directly to these promoters in vivo. This approach has been technically challenging, and due to some difficulty with reproducibility, results have been inconclusive.

Figure 6. Proteasome subunits as potential AtSPL14 targets. Semi-quantitative RT-PCR was

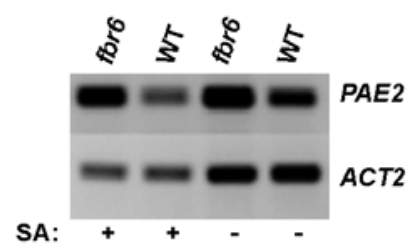
performed with RNA isolated from fbr6 mutant and "wild-type" (WT) plants 8 hours after being subjected to either mock (-) or SA (+) treatments by spraying until run-off ( $1 \mathrm{mM} \mathrm{SA}, 0.01 \%$ Silwet). PCR was performed with oligonucleotide primers that anneal to PAE2 or ACTIN2 as an internal control. Steady-state PAE2 transcript levels are greater in the fbr6 mutant than in wild-type plants regardless of treatment, consistent with the Affymetrix microarray gene expression analyses, and four copies of the AtSPL14 consensus DNA binding site are present in the PAE2 promoter suggesting that AtSPL14 directly modulates PAE2 expression.

\section{Objective \#3) Identify SPL14 modifications and interacting proteins}

The working hypothesis for Objective \#3 is that SPL14 regulates gene expression within a signal complex involving multiple proteins and is redox sensitive.

Much of the progress on this objective is related to generating the appropriate genetic backgrounds and transgenic lines to confirm the in vivo relevance of our in vitro results. Stable transgenic plants that express epitope-tagged versions of SPL14 and the yeast two-hybrid interactors are at various stages of development. In many cases, we are first identifying homozygous knock-out insertion lines to uncover phenotypes and/or facilitate the in vivo protein-protein and protein-DNA interaction assays. We cannot express FBR6 under control of a constitutive promoter, but have observed some expression now under control of the native promoter. However, we have determined that we can effectively immunoprecipitate NTAPi-, HA- and GFP-tagged proteins (in complex) from plant extracts.

\section{References}

Abas, L., Benjamins, R., Malenica, N., Paciorek, T., Wisniewska, J., Moulinier-Anzola, J.C., Sieberer, T., Friml, J., and Luschnig, C. (2006). Intracellular trafficking and proteolysis of the Arabidopsis auxin-efflux facilitator PIN2 are involved in root gravitropism. Nat Cell Biol 8, 249-256.

Arnaud, N., Murgia, I., Boucherez, J., Briat, J.F., Cellier, F., and Gaymard, F. (2006). An ironinduced nitric oxide burst precedes ubiquitin-dependent protein degradation for Arabidopsis AtFer1 ferritin gene expression. J Biol Chem 281, 23579-23588.

Ausubel, F.M., Brent, R., Kingston, R.E., Moore, D.D., Seidman, J.G., Smith, J.A., and Struhl, K. (2006). Current Protocols in Molecular Biology. (New York, NY: John Wiley and Sons).

Birkenbihl, R.P., Jach, G., Saedler, H., and Huijser, P. (2005). Functional dissection of the plantspecific SBP-domain: overlap of the DNA-binding and nuclear localization domains. $J$ Mol Biol 352, 585-596.

Brodersen, P., Petersen, M., Pike, H.M., Olszak, B., Skov, S., Odum, N., Jorgensen, L.B., Brown, R.E., and Mundy, J. (2002). Knockout of Arabidopsis accelerated-cell-death11 encoding a sphingosine transfer protein causes activation of programmed cell death and defense. Genes Dev 16, 490-502.

Brukhin, V., Gheyselinck, J., Gagliardini, V., Genschik, P., and Grossniklaus, U. (2005). The RPN1 subunit of the 26S proteasome in Arabidopsis is essential for embryogenesis. Plant Cell 17, 2723-2737. 
Chen, M., Han, G., Dietrich, C.R., Dunn, T.M., and Cahoon, E.B. (2006). The essential nature of sphingolipids in plants as revealed by the functional identification and characterization of the Arabidopsis LCB1 subunit of serine palmitoyltransferase. Plant Cell 18, 35763593.

Crooks, G.E., Hon, G., Chandonia, J.M., and Brenner, S.E. (2004). WebLogo: a sequence logo generator. Genome Res 14, 1188-1190.

Dietrich, C.R., Han, G., Chen, M., Berg, R.H., Dunn, T.M., and Cahoon, E.B. (2008). Loss-offunction mutations and inducible RNAi suppression of Arabidopsis LCB2 genes reveal the critical role of sphingolipids in gametophytic and sporophytic cell viability. Plant $\mathbf{J}$ 54, 284-298.

Dunn, T.M., Lynch, D.V., Michaelson, L.V., and Napier, J.A. (2004). A post-genomic approach to understanding sphingolipid metabolism in Arabidopsis thaliana. Ann Bot (Lond) 93, 483-497.

Greenberg, J.T., Silverman, F.P., and Liang, H. (2000). Uncoupling salicylic acid-dependent cell death and defense-related responses from disease resistance in the Arabidopsis mutant acd5. Genetics 156, 341-350.

Grundy, W.N., Bailey, T.L., Elkan, C.P., and Baker, M.E. (1997). Meta-MEME: motif-based hidden Markov models of protein families. Comput Appl Biosci 13, 397-406.

Gusmaroli, G., Figueroa, P., Serino, G., and Deng, X.W. (2007). Role of the MPN subunits in COP9 signalosome assembly and activity, and their regulatory interaction with Arabidopsis Cullin3-based E3 ligases. Plant Cell 19, 564-581.

Hara-Nishimura, I., Hatsugai, N., Nakaune, S., Kuroyanagi, M., and Nishimura, M. (2005). Vacuolar processing enzyme: an executor of plant cell death. Curr Opin Plant Biol 8, 404-408.

Hatsugai, N., Kuroyanagi, M., Yamada, K., Meshi, T., Tsuda, S., Kondo, M., Nishimura, M., and Hara-Nishimura, I. (2004). A plant vacuolar protease, VPE, mediates virus-induced hypersensitive cell death. Science $305,855-858$.

Huang, W., Pi, L., Liang, W., Xu, B., Wang, H., Cai, R., and Huang, H. (2006). The proteolytic function of the Arabidopsis $26 \mathrm{~S}$ proteasome is required for specifying leaf adaxial identity. Plant Cell 18, 2479-2492.

Jin, H., Li, S., and Villegas, A., Jr. (2006). Down-regulation of the $26 \mathrm{~S}$ proteasome subunit RPN9 inhibits viral systemic transport and alters plant vascular development. Plant Physiol 142, 651-661.

Kalifa, Y., Gilad, A., Konrad, Z., Zaccai, M., Scolnik, P.A., and Bar-Zvi, D. (2004). The water- and salt-stress-regulated Asr1 (abscisic acid stress ripening) gene encodes a zincdependent DNA-binding protein. Biochem J 381, 373-378.

Kehoe, D.M., and Somerville, S. (1999). DNA microarrays for studies of higher plants and other photosynthetic organisms. Trends in Plant Science 4, 38-41.

Khan, S., and Stone, J.M. (2008). Molecular basis of the dominant Arabidopsis thaliana D-fbr7 fumonisin B1-resistant mutant under revision.

Kim, M., Ahn, J.W., Jin, U.H., Choi, D., Paek, K.H., and Pai, H.S. (2003). Activation of the programmed cell death pathway by inhibition of proteasome function in plants. $J$ Biol Chem 278, 19406-19415.

Kim, M., Lee, S., Park, K., Jeong, E.J., Ryu, C.M., Choi, D., and Pai, H.S. (2006). Comparative microarray analysis of programmed cell death induced by proteasome malfunction and hypersensitive response in plants. Biochem Biophys Res Commun 342, 514-521.

Klein, J., Saedler, H., and Huijser, P. (1996). A new family of DNA binding proteins includes putative transcriptional regulators of the Antirrhinum majus floral meristem identity gene SQUAMOSA. Mol Gen Genet 250, 7-16.

Kropat, J., Tottey, S., Birkenbihl, R.P., Depege, N., Huijser, P., and Merchant, S. (2005). A regulator of nutritional copper signaling in Chlamydomonas is an SBP domain protein that recognizes the GTAC core of copper response element. Proc Natl Acad Sci U S A $102,18730-18735$. 
Kurepa, J., Toh, E.A., and Smalle, J.A. (2008). 26 S proteasome regulatory particle mutants have increased oxidative stress tolerance. Plant $\mathrm{J}$ 53, 102-114.

Kuroyanagi, M., Yamada, K., Hatsugai, N., Kondo, M., Nishimura, M., and Hara-Nishimura, I. (2005). Vacuolar processing enzyme is essential for mycotoxin-induced cell death in Arabidopsis thaliana. J Biol Chem 280, 32914-32920.

Liang, H., Yao, N., Song, J.T., Luo, S., Lu, H., and Greenberg, J.T. (2003). Ceramides modulate programmed cell death in plants. Genes Dev 17, 2636-2641.

Liang, X., Nazarenus, T.J., and Stone, J.M. (2008). Identification of a consensus DNA binding site for the Arabidopsis SBP domain transcription factor, AtSPL14, and binding kinetics by surface plasmon resonance. Biochemistry 47, 3645-3653.

Mach, J.M., Castillo, A.R., Hoogstraten, R., and Greenberg, J.T. (2001). The Arabidopsisaccelerated cell death gene $A C D 2$ encodes red chlorophyll catabolite reductase and suppresses the spread of disease symptoms. Proc Natl Acad Sci U S A 98, 771-776.

Manuel, M., Rallu, M., Loones, M.T., Zimarino, V., Mezger, V., and Morange, M. (2002). Determination of the consensus binding sequence for the purified embryonic heat shock factor 2. Eur J Biochem 269, 2527-2537.

Markham, J.E., and Jaworski, J.G. (2007). Rapid measurement of sphingolipids from Arabidopsis thaliana by reversed-phase high-performance liquid chromatography coupled to electrospray ionization tandem mass spectrometry. Rapid Commun Mass Spectrom 21, 1304-1314.

Markham, J.E., Li, J., Cahoon, E.B., and Jaworski, J.G. (2006). Separation and identification of major plant sphingolipid classes from leaves. J Biol Chem 281, 22684-22694.

Moon, J., Parry, G., and Estelle, M. (2004). The ubiquitin-proteasome pathway and plant development. Plant Cell 16, 3181-3195.

Niu, Y., Chen, K.L., Wang, J.Z., Liu, X., Qin, H.J., Zhang, A.M., and Wang, D.W. (2007). Molecular and functional characterization of sphingosine-1-phosphate lyase homolog from higher plants. Journal of Integrative Plant Biology 49, 323-335.

Pruzinska, A., Tanner, G., Anders, I., Roca, M., and Hortensteiner, S. (2003). Chlorophyll breakdown: pheophorbide a oxygenase is a Rieske-type iron-sulfur protein, encoded by the accelerated cell death 1 gene. Proc Natl Acad Sci U S A 100, 15259-15264.

Pruzinska, A., Tanner, G., Aubry, S., Anders, I., Moser, S., Muller, T., Ongania, K.H., Krautler, B., Youn, J.Y., Liljegren, S.J., and Hortensteiner, S. (2005). Chlorophyll breakdown in senescent Arabidopsis leaves. Characterization of chlorophyll catabolites and of chlorophyll catabolic enzymes involved in the degreening reaction. Plant Physiol 139, 52-63.

Schaller, A. (2004). A cut above the rest: the regulatory function of plant proteases. Planta 220, 183-197.

Schenk, P.M., Kazan, K., Wilson, I., Anderson, J.P., Richmond, T., Somerville, S.C., and Manners, J.M. (2000). Coordinated plant defense responses in Arabidopsis revealed by microarray analysis. Proc Natl Acad Sci U S A 97, 11655-11660.

Shimada, T., Yamada, K., Kataoka, M., Nakaune, S., Koumoto, Y., Kuroyanagi, M., Tabata, S., Kato, T., Shinozaki, K., Seki, M., Kobayashi, M., Kondo, M., Nishimura, M., and HaraNishimura, I. (2003). Vacuolar processing enzymes are essential for proper processing of seed storage proteins in Arabidopsis thaliana. J Biol Chem 278, 32292-32299.

Smalle, J., and Vierstra, R.D. (2004). The ubiquitin 26S proteasome proteolytic pathway. Annu Rev Plant Biol 55, 555-590.

Srinivasasainagendra, V., Page, G., Mehta, T., Coulibaly, I., and Loraine, A.E. (2008). CressExpress: A tool for large-scale mining of expression data from Arabidopsis thaliana. Plant Physiol.

Staswick, P.E. (2008). JAZing up jasmonate signaling. Trends Plant Sci 13, 66-71.

Stone, J.M., Heard, J.E., Asai, T., and Ausubel, F.M. (2000). Simulation of fungal-mediated cell death by fumonisin B1 and selection of fumonisin B1-resistant ( $f b r$ ) Arabidopsis mutants. Plant Cell 12, 1811-1822. 
Stone, J.M., Liang, X., Nekl, E.R., and Stiers, J.J. (2005). Arabidopsis AtSPL14, a plant-specific SBP-domain transcription factor, participates in plant development and sensitivity to fumonisin B1. Plant J 41, 744-754.

Tanaka, R., Hirashima, M., Satoh, S., and Tanaka, A. (2003). The Arabidopsis-accelerated cell death gene $A C D 1$ is involved in oxygenation of pheophorbide a: inhibition of the pheophorbide a oxygenase activity does not lead to the "stay-green" phenotype in Arabidopsis. Plant Cell Physiol 44, 1266-1274.

Tsegaye, Y., Richardson, C.G., Bravo, J.E., Mulcahy, B.J., Lynch, D.V., Markham, J.E., Jaworski, J.G., Chen, M., Cahoon, E.B., and Dunn, T.M. (2007). Arabidopsis mutants lacking long chain base phosphate lyase are fumonisin-sensitive and accumulate trihydroxy-18:1 long chain base phosphate. J Biol Chem 282, 28195-28206.

Vacca, R.A., Valenti, D., Bobba, A., de Pinto, M.C., Merafina, R.S., Gara, L.D., Passarella, S., and Marra, E. (2007). Proteasome function is required for activation of programmed cell death in heat shocked tobacco Bright-Yellow 2 cells. FEBS Lett 581, 917-922.

Wan, J., Dunning, F.M., and Bent, A.F. (2002). Probing plant-pathogen interactions and downstream defense signaling using DNA microarrays. Funct Integr Genomics 2, 259273.

Yang, M., Wardzala, E., Johal, G.S., and Gray, J. (2004). The wound-inducible L/s1 gene from maize is an orthologue of the Arabidopsis Acd1 gene, and the LLS1 protein is present in non-photosynthetic tissues. Plant Mol Biol 54, 175-191.

Yao, N., and Greenberg, J.T. (2006). Arabidopsis ACCELERATED CELL DEATH2 modulates programmed cell death. Plant Cell 18, 397-411.

Zimmermann, P., Hirsch-Hoffmann, M., Hennig, L., and Gruissem, W. (2004). GENEVESTIGATOR. Arabidopsis microarray database and analysis toolbox. Plant Physiol 136, 2621-2632. 


\title{
Arabidopsis AtSPL14, a plant-specific SBP-domain transcription factor, participates in plant development and sensitivity to fumonisin B1
}

Julie M. Stone ${ }^{*}$, Xinwen Liang, Emily R. Nekl ${ }^{\dagger}$ and Justin J. Stiers

Department of Biochemistry and Plant Science Initiative, University of Nebraska-Lincoln, 1901 Vine Street, Lincoln, NE 68588, USA

Received 31 August 2004; revised 7 December 2004; accepted 14 December 2004.

${ }^{*}$ For correspondence (fax +402 472 3139; e-mail jstone2@unl.edu).

${ }^{\dagger}$ Present address: Department of Entomology, University of Nebraska-Lincoln, Lincoln, NE, USA.

\begin{abstract}
Summary
The recessive Arabidopsis thaliana fumonisin B1-resistant ( $\mathrm{fbr}$ ) mutant was identified by its ability to survive in the presence of a programmed cell death $(\bar{P} C \bar{D})$-inducing fungal toxin FB1. The fbr6 mutant also displays altered plant architecture in the absence of FB1, most notably elongated petioles and enhanced leaf margin serration. These phenotypes are a result of a T-DNA insertion in the SQUAMOSA promoter binding protein (SBP) domain gene, AtSPL14. AtSPL14 encodes a plant-specific protein with features characteristic of a transcriptional regulator, including a nuclear localization signal sequence, a plant-specific DNA binding domain (the SBP box), and a protein interaction motif (ankyrin repeats). A transiently expressed fusion of the AtSPL14 protein to green fluorescent protein is directed to the plant nucleus. DNA sequences immediately upstream of the translation start site direct expression of the $\beta$-glucuronidase reporter gene primarily in the vascular tissues, consistent with the phenotypes of the fbr6 mutant. AtSPL14 activates transcription in yeast, with a transactivation domain residing within the $\mathrm{N}$-terminal region of the protein. Recombinant AtSPL14 protein binds $A$. thaliana genomic DNA in vitro in the absence of other proteins. These results indicate that FBR6/SPL14 functions as a transcriptional regulator that plays a role not only in sensitivity to FB1, but also in the development of normal plant architecture.
\end{abstract}

Keywords: Arabidopsis thaliana, transcription, SBP domain, fumonisin B1, programmed cell death.

\section{Introduction}

Cell fate decisions are essential for the growth, development, and survival of multicellular organisms. Programmed cell death (PCD), the intentional elimination of specific cells, is critical for proper development and defense against pathogen infection in both plants and animals. The mechanistic details and molecular components controlling PCD in eukaryotes are not fully understood. However, the pathways appear to be evolutionarily and functionally conserved, given that plant components can function in animals and vice versa (Chae et al., 2003; Dickman et al., 2001; KawaiYamada et al., 2001; Lacomme and Santa Cruz, 1999; Lincoln et al., 2002; Richael et al., 2001). In vascular plants, PCD is a prominent feature of xylem tissue development (Demura et al., 2002; Fukuda, 2000; Groover and Jones, 1999) as well as defense responses to pathogen attack (Beers and McDowell, 2001; Gilchrist, 1998).
Genetic approaches have been used to identify genes involved in plant PCD pathways. For example, mutations that cause plant 'lesion mimic mutants', which spontaneously undergo PCD in the absence of pathogen infection, have revealed roles for lipid metabolism, light perception, and hormone signaling in plant PCD (Brodersen et al., 2002; Gray et al., 2002; Liang et al., 2003; Lu et al., 2003; Mach et al., 2001; Pruzinska et al., 2003; Rate et al., 1999; Vanacker et al., 2001; Yang et al., 2004). We reasoned that identifying plant mutants defective in undergoing PCD in response to pathogens and/or compounds that mimic pathogen infection would provide a complementary genetic approach to investigate the molecular mechanisms regulating PCD.

Fumonisin B1 (FB1) is a fungal toxin that disrupts sphingolipid metabolism in eukaryotes by acting as a competitive inhibitor of ceramide synthase (Desai et al., 
2002). FB1 induces PCD (or apoptosis) in both plants and animals (Asai et al., 2000; Tolleson et al., 1999; Wang et al., 1996) and inhibits growth in yeast (Mao et al., 2000). In Arabidopsis thaliana, FB1 treatment initiates the formation of 'apoptotic bodies' that closely resemble those typically associated with PCD in animal cells, and this FB1-induced cell death is dependent on active transcription and translation, as well as reversible protein phosphorylation (Asai et al., 2000). Moreover, sensitivity to FB1 is dependent on light and the hormone signaling pathways mediated by salicylic acid, jasmonic acid, and ethylene (Asai et al., 2000; Stone et al., 2000).

We exploited the fact that micromolar levels of FB1 inhibit growth of $A$. thaliana seedlings to identify FB1-resistant ( $f b r$ ) mutants. These mutants were selected on FB'-containing agar media at FB1 levels that prevented wild-type plants from developing (Stone et al., 2000). Because FB1 induces PCD and PCD functions in responses to pathogen infection, we predicted that at least some of the $A$. thaliana fbr mutants would also exhibit defense-related phenotypes. Indeed, fbr 1 and $f b r 2$ mutants showed enhanced resistance to virulent bacterial pathogen growth and changes in defense gene induction (Stone et al., 2000). Because FB1 sensitivity is also impacted by light perception and hormone signaling, which are important factors in development, we expected that some $A$. thaliana FB1-resistant mutants might also display altered morphology. A subset of the identified fbr mutants exhibit a characteristic alteration in plant architecture, including elongated petioles and enhanced leaf margin serration.

In this paper, we describe the identification of the gene corresponding to the recessive fbr6 mutant, which displays altered plant architecture in addition to resistance to FB1. The fbr6 mutant phenotypes are the result of a T-DNA insertion in AtSPL 14, a member of the SQUAMOSA PROMOTER BINDING PROTEIN-box (SBP-box) gene family. Functions of SBP-box genes are largely unknown, but they are predicted to act as transcriptional regulators based on the presence of a plant-specific putative DNA binding domain. We further delineate additional functional domains of AtSPL14, and demonstrate that the protein localizes to the nucleus, possesses a transcriptional activation domain and binds Arabidopsis DNA. These data support a role for AtSPL14 as a transcriptional regulator of genes that function in plant development and sensitivity to FB1.

\section{Results}

Isolation, genetic and phenotypic characterization of the fbr6 mutant

The fbr6 mutant was identified in a high-throughput selection for $A$. thaliana mutants resistant to FB1-mediated growth inhibition. Seeds from enhancer trap T-DNA insertion lines (Campisi et al., 1999) were plated on MS-agar supplemented with $0.5 \mu \mathrm{M}$ FB1, and surviving plants were transferred to soil (Stone et al., 2000).

The fbr6 mutant was backcrossed to the parental genotype (Col6 g/1-1), four $F_{1}$ progeny were self-fertilized, and the resulting $F_{2}$ progeny were tested for their ability to survive selection on agar media containing $0.5 \mu \mathrm{M}$ FB1. A chi-square goodness-of-fit test confirmed that the $\mathrm{fbr}$ phenotype of the $F_{2}$ progeny segregated at the expected 3:1 (sensitive:resistant) ratio for a single recessive mutation $\left(\chi^{2}=2.466, n=286\right)$. The FB1-resistant plants were transferred to MS-agar plates lacking FB1 for recovery then transplanted into soil to collect seed. The FB1-resistant $F_{3}$ progeny derived from the backcross exhibited the aberrant plant architecture observed in the original fbr6 mutant (see below).

In addition to resistance to FB1, the fbr6 mutant (grown in the absence of FB1) displays elongated petioles and enhanced leaf margin serration compared with wild-type plants (Figure 1a,b). Transition to flowering occurs a few days later in the fbr6 mutant than in wild-type plants, but no significant alterations in inflorescence branching pattern or floral morphology were observed (Figure 1c). A serrated leaf margin phenotype is associated with altered phase transition during rosette leaf development (Clarke et al., 1999; Prigge and Wagner, 2001). Because developmental phases can be distinguished by venation pattern and the number of water pores or hydathodes (Candela et al., 1999; Poethig, 2003; Tsukaya et al., 2000), we compared wild type and fbr6 mutant leaves that had been cleared with ethanol to reveal venation patterns. The venation patterns of fbr6 and wildtype cotyledons were similar (Figure 1d). However, whereas the venation pattern of the fourth true wild-type leaves generally had five hydathodes as expected for a juvenile leaf (Candela et al., 1999; Clarke et al., 1999), the fourth fbr6 mutant leaves typically resembled mature wild-type leaves with seven hydathodes (Figure 1e). In some cases, the fourth leaf of fbr6 mutants was asymmetrical with six hydathodes (data not shown). These observations suggest that there is a slight acceleration of the juvenile to adult vegetative phase transition in the fbr6 mutant. In contrast to the $f b r 1$ and $f b r 2$ mutants characterized previously (Stone et al., 2000), growth of bacterial pathogens in fbr6 was not significantly different from wild-type plants.

\section{The fbr6 phenotypes are due to T-DNA insertion in the AtSPL14 gene}

Genomic DNA flanking the T-DNA insertion in the fbr6 mutant was recovered using TAIL-PCR (Liu et al., 1995). The DNA sequence of the cloned PCR product indicated that the T-DNA sequences in fbr 6 are inserted on chromosome I in the $3^{\prime}$ UTR region (Figure 1f) of a gene formerly designated as SPL1R2, SQUAMOSA promoter binding protein-like 

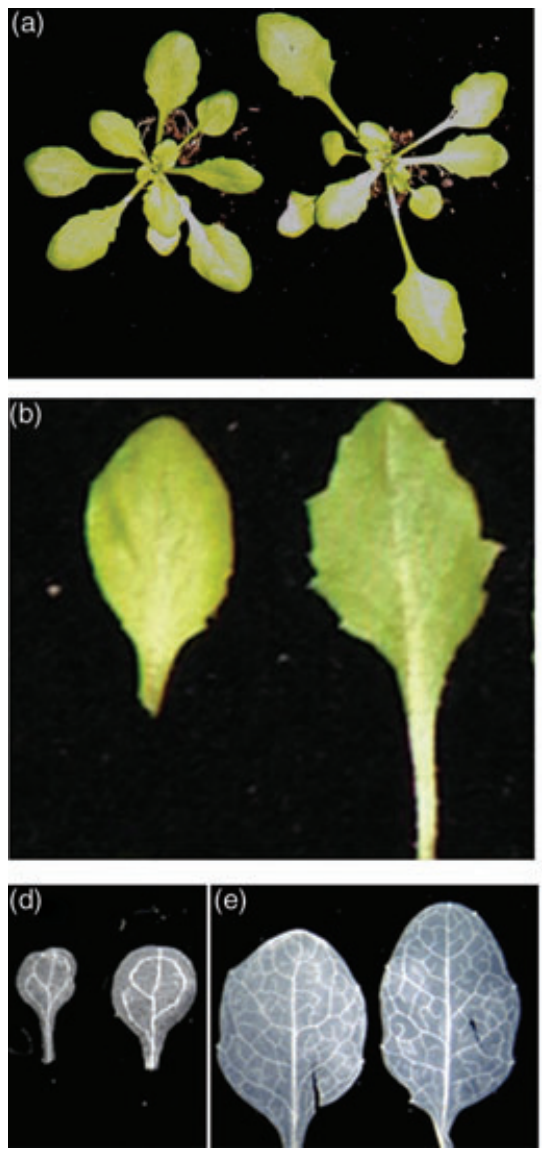

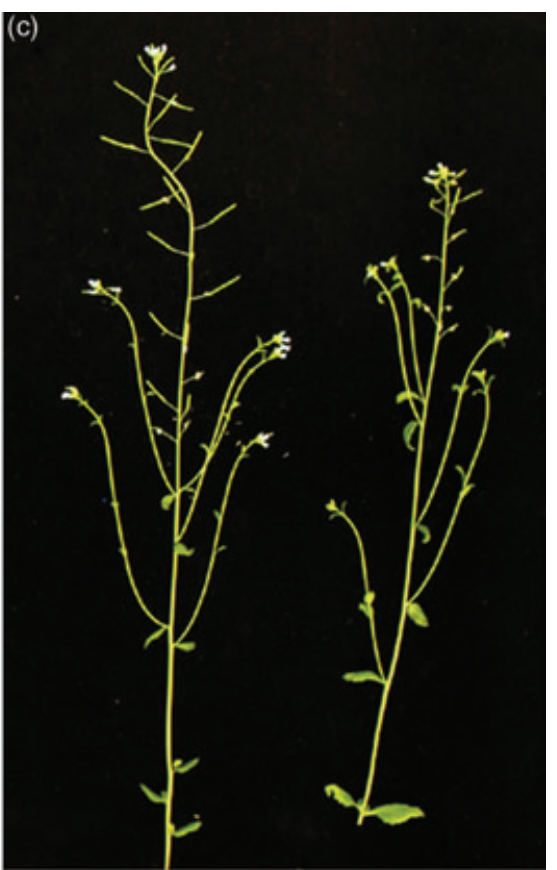

(f)

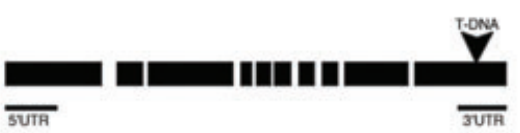

Figure 1. The Arabidopsis thaliana fumonisin B1-resistant6 (fbr6) mutant has altered plant architecture and a T-DNA insertion in the $3^{\prime}$ UTR of the AtSPL14 gene. (a-e) Comparison of the 'wild-type' Col6 gl1-1 (left) with the Col6 g/1-1 fbr6 mutant (right).

(a) Rosette morphology of plants grown in soil with an 8-h photoperiod. The fbr6 mutant displays enhanced leaf margin serration and elongated petioles.

(b) A close up view of the fifth true leaf shows the serrated leaf morphology of fbr6.

(c) Inflorescences show no significant difference in branching pattern or floral morphology, however, the fbr6 mutant transitions to flowering somewhat later than wild type.

(d) The cotyledon venation pattern observed in a dark-field image of cleared tissues displayed no significant differences.

(e) The venation pattern of the fourth true leaf shows five hydathodes for the wild-type leaf, whereas the corresponding fbr6 mutant leaf has seven hydathodes.

(f) Organization of the AtSPL14 (At1g20980) gene based on genomic DNA sequence, EST sequences, and RT-PCR. Exons are represented as black boxes, and the UTRs are underlined. The fbr6 mutant was found to have T-DNA inserted in the $3^{\prime}$ UTR as indicated. related $\underline{2}$ (Cardon et al., 1999). This gene (At1g20980) corresponds to AtSPL14, according to more recent nomenclature for the 16-member squamosa promoter binding protein-like (SPL) gene family (http://www.bio.uni-frankfurt. de/botanik/mcb/AFGN/Huijser.htm).

To verify that the phenotypes observed in fbr6 were due to the disruption of the SPL14 gene, fbr6 transgenic plants harboring a wild-type genomic copy of AtSPL 14 driven by its native promoter were generated. Several independent transgenic lines show that both the sensitivity to FB1 (Figure 2a) and normal plant architecture (Figure 2b) were restored by molecular complementation, indicating that both fbr6 phenotypes are a result of AtSPL14 disruption.

The T-DNA insertion in fbr6 occurs upstream of the predicted polyadenylation signal suggesting that maturation of AtSPL14 mRNA might be defective in the fbr6 mutant. As the AtSPL 14 transcript was undetectable by total RNA Northern blot analyses in both wild-type and fbr6 mutant plants, semiquantitative RT-PCR was performed to determine whether the AtSPL 14 mRNA was expressed in the fbr6 mutant. RNA was isolated from wild type, fbr6 mutant and complemented fbr6 mutant plants. SPL 14 transcripts were detected in wild-type plants, at diminished levels in the fbr6 mutant plants, and at wild-type (or greater) levels in the complemented fbr6 mutant plants (Figure 2c). These data, together with the recessive nature of the $f b r 6$ mutant, verify that the $f b r 6$ phenotypes are due to a reduction-of-function of AtSPL14.

\section{AtSPL14 encodes a putative transcriptional regulator}

AtSPL14 (At1g20980) encodes a 1035 aa protein predicted to function as a plant-specific transcriptional regulator. Analyses of the predicted AtSPL14 protein sequence using the InterPro database (http://www.ebi.ac.uk. InterProScan) revealed that it has a highly conserved SBP DNA binding domain (IPR004333), a Cys- and His-rich region (consensus - $\mathrm{CX}_{4} \mathrm{CX}_{13} \mathrm{HX}_{5} \mathrm{HX}_{15} \mathrm{COOCX}_{3} \mathrm{HX}_{11} \mathrm{C}$ ) found only in plant proteins (Cardon et al., 1999). The founding members of the SBP domain-containing superfamily were originally identified in Antirrhinum majus, where they were identified by their ability to bind to the upstream regulatory region of the SQUAMOSA gene involved in floral meristem identity (Klein et al., 1996). This suggests that the SBP domain of AtSPL14 may also function in DNA binding.

Consistent with the presence of a DNA binding domain, AtSPL14 is predicted to be localized to the plant nucleus. An amino acid sequence (KRSCRRRLAGHNRRRRK) fitting the 
(a) Col6 g/1-1

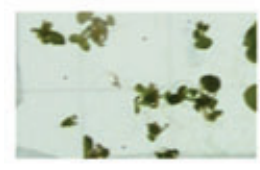

Col6 gl1-1 fbr6

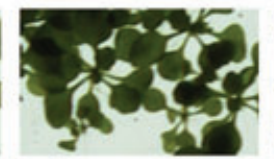

(b)
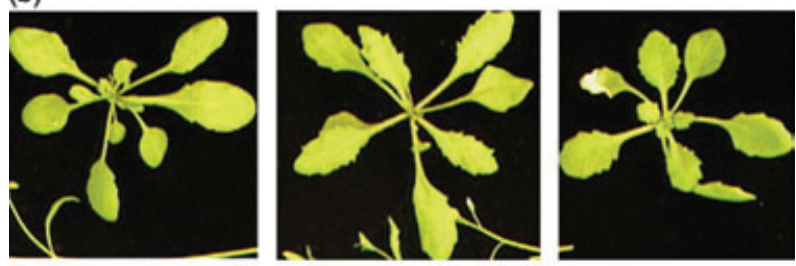

(c)

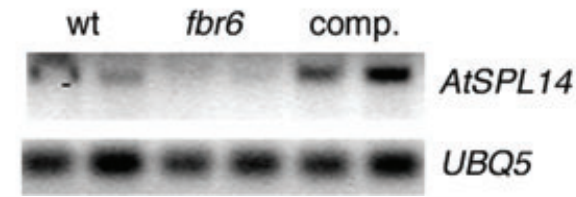

Figure 2. Molecular complementation of the $f b r 6$ mutant with a wild-type genomic DNA copy of the AtSPL14 gene restores fumonisin B1 sensitivity, normal plant morphology, and expression of AtSPL14 mRNA.

(a) Growth of the wild-type parent Col6 g/1-1, Col6 g/1-1 fbr6 mutant, and a homozygous transgenic Col6 g/1-1 fbr6 line transformed with a wild-type copy of the AtSPL14 gene ( $f b r 6+A t S P L 14$ ) on MS plates supplemented with $0.5 \mu \mathrm{m}$ fumonisin B1.

(b) Comparison of 3-week-old soil-grown Col6 g/1-1, Col6 g/1-1 fbr6 mutant, and a molecularly complemented plant ( $f b r 6+A t S P L 14)$.

(c) Semiquantitative RT-PCR was used to detect AtSPL14 transcript accumulation in wild-type, fbr6 mutant, and a molecularly complemented transgenic line. AtSPL 14 mRNA accumulation is reduced in the fbr6 mutant and is restored by molecular complementation of the $\mathrm{fbr} 6$ mutant with the wild-type AtSPL 14 gene. Accumulation of transcripts corresponding to UBQ5 was used as a control.

consensus for a bipartite nuclear localization signal (NLS) was found within the highly conserved SBP DNA binding domain (aa 117-193), using PSORT (http://psort.nibb.ac.jp) for prediction of protein localization (Robbins et al., 1991).

The InterPro analysis also revealed that the AtSPL14 protein possesses ankyrin repeats (IPR002110) in the Cterminal region of the protein (aa 821-941). Ankyrin repeats are a common protein-protein interaction motif consisting of approximately 33 amino acid modules found in transcription factors and other eukaryotic proteins (Dechend et al., 1999; Ely and Kodandapani, 1998; Niggeweg et al., 2000). These analyses of the predicted protein encoded by the AtSPL14 gene indicate that it is likely to function as a transcriptional regulator.

\section{AtSPL14 is expressed in vascular tissues and floral organs}

To determine the spatial and developmental expression pattern of AtSPL14, we generated transgenic plants harboring the DNA sequence immediately upstream of the translation start site of AtSPL14 fused to the $\beta$-glucuronidase (GUS) reporter gene. The AtSPL14 'promoter'::GUS fusion was transformed into wild-type (Col-0) plants, and several independent transgenic plants homozygous for the transgene were analyzed by histochemical staining for GUS activity.

Under the influence of the AtSPL14 'promoter' expression of the GUS gene was detected primarily in the vascular tissues of aerial portions of the plant. No GUS activity was detected in the hypocotyl (Figure 3a), while strong staining was observed predominantly in the leaf petioles and the primary vascular tissues of both leaves (Figure $3 a, b$ ) and cotyledons (Figure 3c). In leaves, there was intense staining in the hydathodes (Figure 3b), and somewhat lower levels in the secondary vascular of leaves (Figure 3b) and cauline leaves (data not shown). GUS activity was occasionally detected in root tissues of plants grown on agar, but not in plants grown in soil. GUS-dependent staining in the vascular tissues of inflorescences and at the base and tips of developing siliques post-pollination increased during seed formation and persisted through maturation (Figure $3 \mathrm{~d}$ ).

\section{AtSPL14 localizes to the nucleus}

The presence of a putative bipartite NLS in AtSPL14 suggested that it would be localized to the plant nucleus (Robbins et al., 1991). The AtSPL14 cDNA was cloned into the binary vector $p E G A D$ to produce an in-frame fusion downstream of the green fluorescent protein (GFP) (Cutler et al., 2000). Transient transformation of Nicotiana tabacum leaves was achieved by 'agroinfiltration' (Yang et al., 2000), and subcellular localization of GFP was visualized by confocal microscopy (Figure 4). Controls showed GFP expressed throughout the cytoplasm (Figure 4a,b), whereas the GFP-AtSPL14 fusion was targeted to the nucleus (Figure 4c,d).

\section{AtSPL14 activates transcription in yeast and binds}

\section{A. thaliana DNA}

AtSPL14 was tested for its ability to activate transcription in yeast when fused to the GAL4 DNA binding domain. cDNAs encoding the entire AtSPL14 protein or various deletions were fused in-frame to sequences encoding the GAL4 DNA binding domain and transformed into yeast strain AH109 containing GAL4-responsive upstream activator sequence (UAS) binding sites upstream of different reporter genes. The ability of these GAL4BD/AtSPL14 fusion proteins to activate transcription was assessed by the ability to grow in the absence of histidine (conferred by the HIS3 reporter gene) and to induce $\alpha$-galactosidase activity (conferred by the MEL1 reporter gene). A GAL4BD fusion to AtSPL14 activated transcription in yeast, while the control (GAL4BD alone) failed. Deletion analyses suggest that the capacity to activate transcription in yeast resides within the $\mathrm{N}$-terminal 184 amino acid residues of AtSPL14 (Figure 5). 
To assess whether AtSPL14 binds to $A$. thaliana genomic DNA sequences, recombinant fusion proteins were produced in Escherichia coli. Maltose binding protein (MBP)
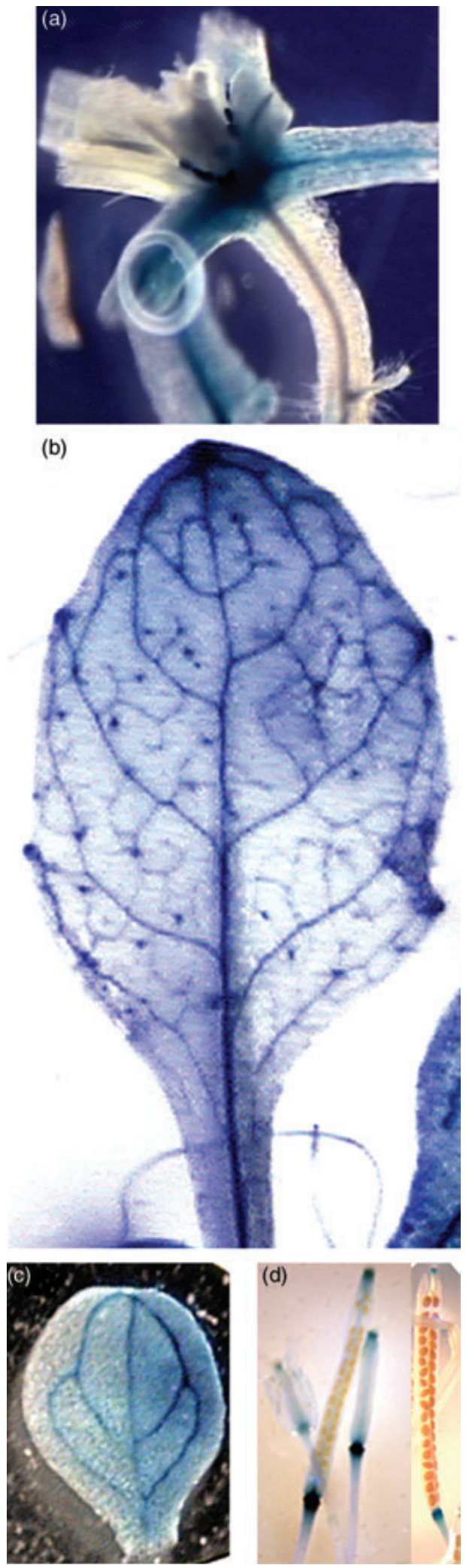
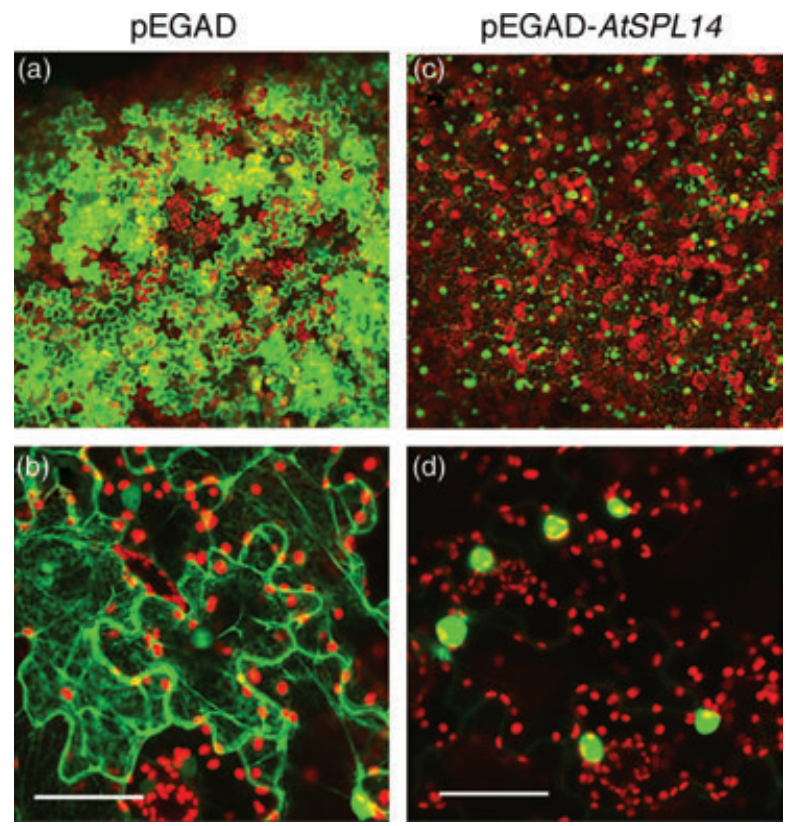

Figure 4. Nuclear localization of a GFP-AtSPL14 fusion protein. Tobacco leaves were transiently transformed with Agrobacterium tumefaciens carrying either a control vector $\mathrm{pEGAD}$ or $\mathrm{pEGAD}-A t S P L 14$ to produce an in-frame GFP-AtSPL14 fusion protein. Images were obtained by confocal laser scanning microscopy and merged Z-series images are shown.

(a, b) Transformation with pEGAD shows expression of GFP throughout the cytoplasm.

(c, d) Transformation with pEGAD-AtSPL14 shows GFP localized primarily to the nucleus.

(a) and (c) are low magnification images, while (b) and (d) are high magnification images (bar $=50 \mu \mathrm{m}$ ).

and a MBP fusion to the N-terminal 409 residues of AtSPL14 (encompassing the SBP domain) were immobilized on a PVDF membrane and incubated with ${ }^{32} \mathrm{P}$-labeled $A$. thaliana genomic DNA. The $A$. thaliana genomic DNA bound to the MBP-FBR6 fusion protein, but did not bind to the MBP control protein (Figure 6). Therefore, AtSPL14 binds to target sequences in the $A$. thaliana genome in the absence of other proteins.

\section{Discussion}

The existence of small gene families encoding the putative DNA-binding SBP domain in plants has been known for over a decade. However, little is known of the physiological functions of these putative transcriptional regulators beyond

Figure 3. DNA sequences immediately upstream of the translation start site for the AtSPL14 gene drives expression of the $\beta$-glucuronidase (GUS) reporter gene in several plant tissues. Histochemical staining for $\beta$-glucuronidase activity was performed on homozygous transgenic $T_{3}$ and $T_{4}$ plants harboring a AtSPL14::GUS fusion construct. The upstream region of AtSPL14 drives expression of GUS in: (a) the vascular tissues of leaf petioles, but not the hypocotyl; (b) the vascular tissues of petioles and true leaves, the hydathodes, and the base of trichomes; (c) the vascular tissue of cotyledons; and (d) the stigma and base of inflorescences and developing siliques post-pollination. 


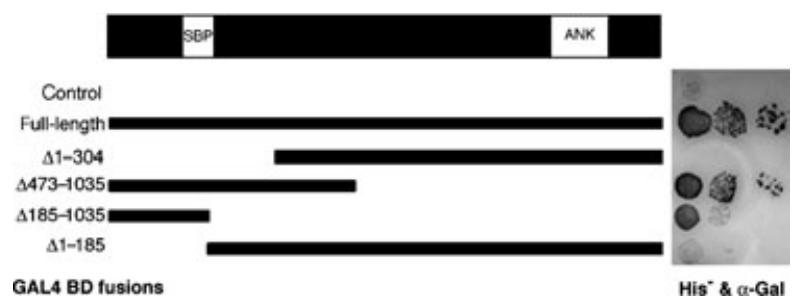

Figure 5. Transcriptional activation activity of AtSPL14 in a modified yeast two-hybrid assay. Schematic representation of the protein encoded by AtSPL14 showing positions of the 'SBP' DNA binding domain and the ankyrin-repeat region (ANK). GAL4 DNA binding domain (BD) fusions to portions of AtSPL14 expressed in a yeast strain AH109 carrying the GAL4responsive upstream activator sequences upstream of the HIS3 and MEL 1 reporter genes. Ability to grow in the absence of exogenous histidine (His-) and $\alpha$-galactosidase activity ( $\alpha$-GAL) of individual fusion proteins is shown. Serial dilutions of yeast harboring the indicated GAL4 BD fusions to AtSPL14 were spotted onto plates lacking histidine and supplemented with $\mathrm{X}-\alpha-\mathrm{GAL}$. These data indicate that AtSPL14 can activate transcription in a heterologous eukaryotic system, and that a transcriptional activation domain resides in the $\mathrm{N}$-terminal 184 amino acids of AtSPL14.

their ability to bind DNA (Cardon et al., 1999; Klein et al., 1996; Riechmann et al., 2000). Only two SBP domaincontaining gene mutants with observable phenotypes have been previously described. The $A$. thaliana spl8 mutant has reduced fertility due to the function of AtSPL8 in pollen sac development (Unte et al., 2003). The Zea mays liguleless 1 mutation affects plant development at the boundary between the leaf blade and sheath, and the LIGULELESS1 protein was also shown to be nuclear-localized, consistent with its presumed function as a transcription factor (Moreno et al., 1997). Our T-DNA insertion in the 3'UTR of the AtSPL 14 gene provides the third example of an observable phenotype in an SBP domain-containing gene mutant. This insertion reduces the levels of AtSPL14 mRNA and causes both the FB1-resistant and altered plant architecture phenotypes associated with the fbr6 mutant.

The FB1-resistant ( $f b r$ ) mutant screen was designed to identify components of plant PCD pathways, which have been linked to sphingolipid metabolism, light perception,

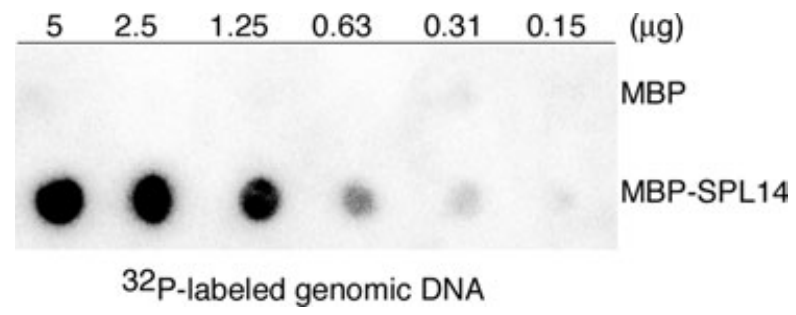

Figure 6. Recombinant AtSPL14 binds Arabidopsis thaliana genomic DNA in the absence of additional proteins. Purified recombinant fusion proteins (MBP and MBP-AtSPL14) were immobilized on a membrane (Hybond-N; Amersham Biosciences) and incubated with ${ }^{32} \mathrm{P}$-labeled $A$. thaliana genomic DNA. Recombinant fusion protein containing the SBP domain of AtSPL14 binds to DNA, while the control protein MBP alone fails to bind to DNA. and hormone signaling (Brodersen et al., 2002; Gray et al., 2002; Liang et al., 2003; Lu et al., 2003; Mach et al., 2001; Pruzinska et al., 2003; Rate et al., 1999; Vanacker et al., 2001; Yang et al., 2004). Several of the identified fbr mutants (including fbr6) display abnormal plant architecture. However, because sensitivity to FB1 is influenced by hormone signaling and light (Asai et al., 2000; Stone et al., 2000), perturbation of these or other signal transduction pathways could be responsible for the altered plant architecture of fbr6.

Analysis of several $\mathrm{fbr}$ mutants has revealed differing phenotypes. For example, the previously characterized fbr 1 and fbr2 mutants were less susceptible to the virulent bacterial pathogen Pseudomonas syringae pv. maculicola (Stone et al., 2000). In contrast, growth of virulent and avirulent strains of $P$. syringae pv. maculicola in the fbr 6 mutant was not significantly different from the wild type using the same assay conditions (data not shown).

The FB1 sensitivity of adult fbr6 mutant leaves, assayed by leaf infiltration (Asai et al., 2000) followed by quantitative electrolyte leakage measurements, was not significantly different from wild type, and a subset of the other $\mathrm{fbr}$ mutants fail to show resistance to FB1 in the leaf infiltration assays (J.M. Stone, unpublished data).

While the fbr mutants were all identified by the ability to germinate and develop in the presence of FB1, differences among the fbr mutants in sensitivity to FB1 in mature leaves and protoplasts might be due to cell type-specific expression. Only mutations in genes expressed in certain tissues during early development are likely to be identified in the $\mathrm{fbr}$ selection scheme. But if these genes are not highly expressed in mature leaf cells, the mutants will fail the FB1 resistance tests in the leaf infiltration and protoplast assays. Cell type-specific expression of AtSPL14 is a possible explanation for the observed sensitivity to FB1 and pathogen infection in mature leaves of the fbr6 mutant.

\section{Expression of AtSPL14 and the fbr6 phenotype}

The expression patterns observed for the AtSPL14 'promoter'::GUS reporter construct are generally consistent with the leaf abnormalities associated with the fbr6 mutant. The most obvious morphological defects in the fbr6 mutant are elongated petioles, serrated leaf margins, and an accelerated vegetative phase change. The AtSPL 14 'promoter' drives GUS expression in the vascular tissues of petioles, so reduced levels of this transcription factor are consistent with altered petiole development. Other $A$. thaliana mutants with elongated petioles have been described, including lightsensing phyB mutant linked to hormone signaling pathways (Genoud et al., 2002; Morelli and Ruberti, 2002; Tsukaya et al., 2002).

Significant expression was also observed in the leaf vascular tissues. The two major tissue types of the plant 
vasculature, xylem and phloem, are composed of multiple cell types. Phloem tissue consists of at least two differentiated cell types - sieve cells and companion cells, whereas xylem tissue contains tracheary elements that differentiate from provascular cells by a process of programmed cell death (PCD) and subsequent lignification (Demura et al., 2002; Fukuda, 2000; Groover and Jones, 1999). Therefore, altered xylem differentiation might contribute to the altered plant architecture of the fbr6 mutant.

The fbr6 mutant appears to have a truncated juvenile phase, producing 'adult' leaves earlier than wild-type plants. Vegetative phases are distinguished by venation pattern, hydathode numbers, and the capacity to produce trichomes (Candela et al., 1999; Poethig, 2003; Tsukaya et al., 2000). AtSPL14-driven expression in these tissues - leaf vasculature, hydathodes, and the base of trichomes - resembles the patterns observed with the auxin-responsive marker, DR5::GUS (Aloni et al., 2003). Hydathode numbers were used to assess leaf phases, as the fbr6 mutant was isolated in a trichome-less (g/1-1) background. It will be interesting to know whether the early 'adult' leaves also have trichomes in a different background. The serrated leaf margin phenotype is shared with other mutants with accelerated phase changes (Berardini et al., 2001; Bollman et al., 2003; Candela et al., 1999; Clarke et al., 1999). Zinc finger transcription factors, such as SERRATE and JAGGED (Clarke et al., 1999; Ohno et al., 2004; Prigge and Wagner, 2001), might represent transcriptional regulators that act in concert with AtSPL14.

The expression at the base of siliques and in the stigma does not correlate with any gross morphological defects in the mutant, however, the base of siliques is the site of floral organ abscission requiring PCD (Jinn et al., 2000).

\section{Molecular characterization of AtSPL14}

The N-terminal region of AtSPL14 (aa 1-184) exhibited transcriptional activation in yeast. The structural basis of transcriptional activation domains is essentially unknown, however, 'typical' transcriptional activation domains such as glutamine-rich or acidic regions were not detected in this region. The prevalent proline, serine, and threonine residues (approximately 20\%) might comprise a transcriptional activation domain functionally similar to those described for some mammalian transcription factors (Liu et al., 2003; Prado et al., 2002). AtSPL14 is also rich in hydrophobic leucine residues. Three putative EAR motifs ( $L X L X L$, aa 81-85, 388-392, 459-463), which function as a transcriptional repression domains in several plant transcription factors (Hiratsu et al., 2002, 2003; Ohta et al., 2001; Tiwari et al., 2004), and five LLXXL motifs, which mediate interactions between transactivation domains and eukaryotic coactivators (Chen, 1999; Heery et al., 1997) were detected. Further analyses are necessary to validate the importance of these motifs in AtSPL14.

Secondary structure predictions of AtSPL14 (aa 120-194) comprising the SBP domain suggested that this region may form a helix-loop-helix structure commonly found in many DNA binding proteins (Massari and Murre, 2000; Tan and Richmond, 1998). The highly conserved SBP DNA binding domain (consensus - $\mathrm{CX}_{4} \mathrm{CX}_{13} \mathrm{HX}_{5} \mathrm{HX}_{15} \mathrm{COOCX}_{3} \mathrm{HX}_{11} \mathrm{C}$ ) is particularly rich in $\mathrm{Cys}$ and $\mathrm{His}$ residues. Although $\mathrm{Cys} / \mathrm{His}$ rich DNA-binding regions of proteins often function to coordinate zinc, the SBP domain sequence does not correspond to any previously described zinc finger motifs (Dietrich et al., 1997; Laity et al., 2001). A recent report describing the solution structures of the SBP domains from SPL4 and SPL7 suggest that these do indeed coordinate two zinc ligands (Yamasaki et al., 2004). We have verified that recombinant AtSPL14 is capable of binding to $A$. thaliana genomic DNA. However, incubation of recombinant AtSPL14 protein with metal-chelating compounds, EDTA or o-phenanthroline, had no significant effect on DNA binding activity (data not shown), similar to results with the $A$. majus SBP proteins (Klein et al., 1996).

AtSPL14 contains a C-terminal extension lacking in AtSPL8 and LIGULELESS1. This C-terminal extension contains ankyrin repeats, which are found in a number of DNAbinding transcriptional regulators and partner proteins (Dechend et al., 1999; Ely and Kodandapani, 1998; Niggeweg et al., 2000). Because combinatorial control of gene expression plays a critical role in achieving functional diversity (Chen and Hampsey, 2002; Messenguy and Dubois, 2003), AtSPL14 is likely to function in concert with other proteins through its ankyrin repeats.

Identification of direct target genes of AtSPL14 and AtSPL14 regulatory partners should enhance our understanding of transcription regulation in vegetative development and/or FB1 resistance. Moreover, the finding that the fbr6 mutant phenotypes are due to the T-DNA disruption in AtSPL14 will facilitate genetic interaction analyses with other plant mutants to link the developmental alterations with FB1 resistance.

\section{Experimental procedures}

\section{Arabidopsis thaliana growth and isolation of the fbr6 mutant}

For isolation of the $\mathrm{fbr} 6$ mutant, seed pools obtained from the ABRC (CS31087) were surface-sterilized with $50 \%$ bleach, $0.02 \%$ Tween- 20 for $15 \mathrm{~min}$, rinsed three times with sterile $\mathrm{H}_{2} \mathrm{O}$, and sowed on Murashige-Skoog media supplemented with $2 \%$ sucrose, $0.8 \%$ phytagar and $0.5 \mu \mathrm{m}$ fumonisin B1 as described (Stone et al., 2000). Plants were grown in soil (Metro-Mix 360; Scotts, Maryville, $\mathrm{OH}$, USA) in a growth chamber (Percival AR36L; Percival, Perry, IA, USA) at $22^{\circ} \mathrm{C}, 70 \% \mathrm{RH}$ and approximately $100 \mu \mathrm{E} \mathrm{m} \mathrm{mec}^{-1} \mathrm{sen}^{-1}$ under coolwhite fluorescent lights supplemented with incandescent lamps, with either an 8 or $12 \mathrm{~h}$ photoperiod. 


\section{Identification of the T-DNA disruption in AtSPL14}

The fbr6 mutant was identified from a population of Col-6 g/1-1 plants transformed with the enhancer trap vector pD991 (Campisi et al., 1999). Thermal asymmetric interlaced PCR, TAIL-PCR, was used to rescue the DNA flanking the right border sequence using nested oligonucleotide primers corresponding to the right border of pD991 (oligo123, oligo124 and oligo86; http://www.dartmouth.edu/ $\sim$ tjack// and primer TAIL-AD2 5'-ngtcgaswganawgaa-3' as described (Campisi et al., 1999; Liu et al., 1995). The PCR product from the tertiary reaction was cloned into pGEM-TEasy (Promega, Madison, WI, USA) and subjected to DNA sequencing with T7 and SP6 oligonucleotide primers.

\section{Semiquantitative RT-PCR}

Total RNA was isolated from individual 3-week-old plants using the Qiagen RNeasy midi kit (Valencia, CA, USA) according to manufacturer's instructions. The RNA was treated with DNase I using a DNA-free ${ }^{T M}$ kit (Ambion, Inc., Austin, TX, USA). RNA concentration was determined spectrophotometrically. Reverse transcription was performed in a $20 \mu \mathrm{l}$ reaction with $1 \mu \mathrm{g}$ total RNA, $0.5 \mu \mathrm{g}$ oligo $(\mathrm{dT})_{18}$ primer, $40 \mathrm{U}$ RNasin (Promega), $500 \mu \mathrm{M}$ dNTPs, and $40 \mathrm{U} \mathrm{M}-\mathrm{MuLV}$ reverse transcriptase (Fermentas, Hanover, MD, USA), then diluted to $50 \mu \mathrm{l}$. PCR was performed for 40 cycles $94^{\circ} \mathrm{C} 30 \mathrm{sec}$, $52^{\circ} \mathrm{C} 30 \mathrm{sec}, 72^{\circ} \mathrm{C} 1.5 \mathrm{~min}$ in a reaction containing $100 \mu \mathrm{m}$ dNTPs, $1 \mathrm{mM} \mathrm{MgCl}$, $250 \mathrm{~nm}$ oligonucleotide primers. Oligonucleotide primers were cFBR6F7: '5-CCGCTTCAAGTTTTTGCT-3'; cFBR6STOPSma: 5'-CCTCCCGGGTATAGTTCTCTAGATTGAGCCATAATCC-3'; UB05-F: 5'-GTGGTGCTAAGAAGAGGAAGA-3'; UBO5-R: 5'-TCAAGCTTCAACTCCTTCTTT- $3^{\prime}$. The AtSPL14 primers were designed to span an intron to exclude DNA contamination. The primers correspond to exon 9 and the region encompassing the STOP codon in exon 10 (154 bp upstream of the T-DNA insertion site in fbr6).

\section{Molecular complementation and promoter::GUS reporter gene fusions}

The wild-type AtSPL14 gene containing $1448 \mathrm{bp}$ upstream of the ATG start codon and $443 \mathrm{bp}$ downstream of the STOP codon was amplified from $A$. thaliana Col-0 genomic DNA by PCR using oligonucleotide primers 'prom Smal $F^{\prime}$ : 5'CCTCCCGGGTTGAGGTTCGAAATAACGTGGTCAAG-3' and 'polyA Smal R': 5'-CCTCCCGGGTTATGCATTTTGACTTTCGAGAATAAG-3'. A fragment corresponding to only the $1448 \mathrm{bp}$ upstream of the ATG start codon was amplified from $A$. thaliana Col-0 genomic DNA by PCR using oligonucleotide primers 'prom Smal F' and 'prom Smal $\mathrm{R}^{\prime}: 5^{\prime}$-CCTCCCGGGATCTCTCGATCTGAGTCTGACCCTTTTTC-3'. The resulting fragments were subcloned in pGEM-TEasy (Promega), and fidelity of the PCR was confirmed by DNA sequencing.

The fragment containing the entire promoter and coding sequence (full-length) for molecular complementation was cloned into pCAMBIA 3300, and the FBR6 promoter only (pFBR6) fragment was cloned into $\mathrm{PCAMBIA} 3301$, both vectors carry a gene that confers resistance to the herbicide, Basta ${ }^{\mathrm{TM}}$. These constructs were transformed into Agrobacterium tumefaciens strain GV3101 MP90 by electroporation. Col-6 g/1-1 fbr6 plants and Col-0 plants were transformed with 3300FBR6 'full-length' and 3301pFBR6, respectively, by the floral dip method (Clough and Bent, 1998). Primary transformants were selected on soil by spraying with a 1:100 dilution of Finale ${ }^{\mathrm{TM}}$ (AgrEvo Environmental Health, Montvale, NJ, USA). Transgenic lines homozygous for single insertions were selected by analyzing the segregation of herbicide resistance in $T_{2}$ and $T_{3}$ populations.
Molecular complementation of the fbr6 mutant phenotypes was assessed by sowing wild-type, fbr6 mutant and 'complemented' seeds on MS-agar media supplemented with $2 \%$ sucrose $(\mathrm{w} / \mathrm{v})$ and $0.5 \mu \mathrm{m}$ FB1. Reversion of the morphological phenotype was assessed visually in soil-grown plants.

Tissue expression of the AtSPL14 'promoter'::GUS construct was assessed by histochemical staining of several independent transgenic lines at different stages of development using 5-bromo-4-chloro-3-indolyl- $\beta$-glucuronic acid as a substrate (Jefferson, 1987).

\section{Nuclear localization of FBR6}

The AtSPL 14 cDNA was amplified from reverse-transcribed RNA by $\mathrm{PCR}$ using oligonucleotide primers with engineered $\mathrm{BamHI}$ restriction sites SBPF2: 5'-GGATCCAAATGGATGAGGTAGGAGCTCAAGTG-3' and SBPR: $5^{\prime}$-ACTAGTCCGGATCCGATTGAGCCATAATCCAAACCTCC-3'. The resulting AtSPL14 CDNA fragment was cloned into pGEM-TEasy (Promega) and subjected to DNA sequencing. A BamHI fragment was cloned into the appropriately digested binary vector $p E G A D$ to produce an in-frame fusion to GFP (Cutler et al., 2000). pEGAD with no insert and pEGAD-AtSPL14 were transformed into A. tumefaciens strain GV3101 MP90 by electroporation. The resulting strain was grown overnight at $30^{\circ} \mathrm{C}$ with shaking in LB supplemented with $25 \mathrm{mg} \mathrm{I}^{-1}$ rifampicin, $50 \mathrm{mg} \mathrm{I}^{-1}$ gentamycin and $50 \mathrm{mg} \mathrm{l}^{-1}$ kanamycin, pelleted at $3000 \mathrm{~g} 5 \mathrm{~min}$ and diluted to an $\mathrm{OD}_{600}$ of 1 in $10 \mathrm{~mm}$ MES pH 5.6, $10 \mathrm{~mm} \mathrm{MgCl}, 100 \mu \mathrm{m}$ acetosyringone (Sigma-Aldrich, St Louis, MO, USA). Transient transformation of $N$. tabacum leaves was achieved by 'agroinfiltration' by infiltrating the strains into leaves using a syringe without a needle (Goodin et al., 2002; Schob et al., 1997; Yang et al., 2000). After $48 \mathrm{~h}$, GFP was visualized with a laser scanning confocal microscope (BioRad MRC-1024ES) and analyzed using BioRad LaserSharp (v3.3) software (Bio-Rad, Hercules, CA, USA). Images shown were merged from Z-series scans.

\section{Transcriptional activation assays in yeast}

The Saccharomyces cerevisiae strain AH109 and the GAL4 binding domain vector pGBKT7 used to test transcriptional activation in yeast were obtained from BD Biosciences as part of the Matchmaker Two-Hybrid System 3 (Clontech, Palo Alto, CA, USA). The full-length cDNA (a BamHl fragment using engineered restriction enzyme sites) and various truncated versions $(\mathrm{Ncol} / \mathrm{BamHI}, \Delta 1-304 ; \mathrm{BamHI} / P s t \mathrm{l}$ $\Delta 473-1035 ; \mathrm{BamHI} / \mathrm{Ball}, \Delta 185-1035 ; \mathrm{Ball} / \mathrm{BamHI}, \Delta 1-185)$ were generated by restriction enzyme digestions and cloned into appropriately digested vector preparations of pGBKT7 to produce in-frame fusions to the GAL4 DNA binding domain. Constructs were transformed into yeast strain AH109 that has GAL4-recognized UAS driving expression of four different reporter genes and selected on media lacking tryptophan. Yeast were grown at $30^{\circ} \mathrm{C}$ with shaking. The ability of the AtSPL14 protein to activate transcription in yeast was assayed by the ability to grow in the absence of histidine (conferred by the HIS3 reporter gene) and histochemical detection of $\alpha$-galactosidase activity (conferred by the MEL1 reporter gene). Cell counts of individual strains were determined by with a hemacytometer. Serial dilutions were plated on media lacking histidine and supplemented with 5-bromo-4-chloro-3-indolyl- $\alpha$-galactopyranoside (X- $\alpha$-Gal; $\left.40 \mathrm{mg} \mathrm{l}^{-1}\right)$. The GAL4 binding domain fusion proteins also contained a c-myc epitope. Expression of the various GAL4BD/FBR6 fusion proteins was confirmed by Western blot analysis using a monoclonal antibody against the c-myc epitope (data not shown). 


\section{Recombinant protein expression, purification, and DNA binding assay}

To assess whether the SBP domain of AtSPL14 is capable of binding to $A$. thaliana genomic DNA sequences, recombinant fusions proteins were produced in E. coli strain Rosetta (EMD Biosciences, San Diego, CA, USA). A BamHI/Xbal fragment of the AtSPL14 cDNA was cloned into vector pMalK (derived from pMalcRI) and affinitypurified with amylose-agarose (New England Biolabs, Beverly, MA, USA). pMalK-FBR6s produces a recombinant protein of maltose binding protein in-frame with the N-terminal 409 amino acids of AtSPL14, encompassing the SBP domain. Purity was confirmed by SDS-PAGE analysis (Laemmli, 1970), and protein concentration was determined with the BCA protein assay according to the manufacturer's instructions (Pierce Biotechnology, Rockford, IL, USA) using bovine serum albumin as a standard. Dilutions of MBP alone and an MBP fusion to the N-terminal 409 amino acid residues of FBR6 were spotted onto a PVDF membrane (Hybond-P; Amersham Biosciences, Piscataway, NJ, USA) in 'binding buffer' ( $25 \mathrm{~mm}$ Hepes- $\mathrm{KOH}$ $\mathrm{pH} 7.4,50 \mathrm{~mm} \mathrm{NaCl}, 1 \mathrm{~mm}$ DTT). The membrane was blocked in 'binding buffer' supplemented with $5 \%$ dry milk and probed with 'binding buffer' supplemented with $1 \%$ dry milk and randomprimed ${ }^{32} \mathrm{P}$-labeled $A$. thaliana genomic DNA (Sambrook and Russell, 2001). The membrane was washed three times with 'binding buffer' plus $1 \%$ milk and analyzed with a Bio-Rad Molecular FX and QuantityOne software (Bio-Rad).

\section{Acknowledgements}

We are grateful to the Arabidopsis Biological Resource Center (Ohio State University) for genetic resources, Christian Elowsky for assistance with the confocal microscopy, Tara Nazarenus for excellent technical assistance, and other members of the Stone laboratory for helpful discussion. This work, initiated in Frederick M. Ausubel's laboratory (Dept. of Molecular Biology, Massachusetts General Hospital, Boston, MA), was supported by the National Institutes of Health (GM-48707 to F.M.A.) and the National Science Foundation (DBI-9750297 to J.M.S.). Work at the University of Nebraska-Lincoln was partially supported by NIH grant no. P20 RR017675 from the National Center for Research Resources, and National Science Foundation grant no. IBN-0221925A, its contents are solely the responsibility of the authors and do not necessarily represent the official views of the NIH. This is a contribution of the University of Nebraska Agricultural Research Division, Lincoln, NE 68583. Journal Series No. 14541.

\section{References}

Aloni, R., Schwalm, K., Langhans, M. and Ullrich, C.I. (2003) Gradual shifts in sites of free-auxin production during leaf-primordium development and their role in vascular differentiation and leaf morphogenesis in Arabidopsis. Planta, 216, 841-853.

Asai, T., Stone, J.M., Heard, J.E., Kovtun, Y., Yorgey, P., Sheen, J. and Ausubel, F.M. (2000) Fumonisin B1-induced cell death in Arabidopsis protoplasts requires jasmonate-, ethylene-, and salicylate-dependent signaling pathways. Plant Cell, 12, 1823-1836.

Beers, E.P. and McDowell, J.M. (2001) Regulation and execution of programmed cell death in response to pathogens, stress and developmental cues. Curr. Opin. Plant Biol. 4, 561-567.

Berardini, T.Z., Bollman, K., Sun, H. and Poethig, R.S. (2001) Regulation of vegetative phase change in Arabidopsis thaliana by cyclophilin 40 . Science, 291, 2405-2407.
Bollman, K.M., Aukerman, M.J., Park, M.Y., Hunter, C., Berardini, T.Z. and Poethig, R.S. (2003) HASTY, the Arabidopsis ortholog of exportin 5/MSN5, regulates phase change and morphogenesis. Development, 130, 1493-1504.

Brodersen, P., Petersen, M., Pike, H.M., Olszak, B., Skov, S., Odum, N., Jorgensen, L.B., Brown, R.E. and Mundy, J. (2002) Knockout of Arabidopsis accelerated-cell-death11 encoding a sphingosine transfer protein causes activation of programmed cell death and defense. Genes Dev. 16, 490-502.

Campisi, L., Yang, Y., Yi, Y., Heilig, E., Herman, B., Cassista, A.J., Allen, D.W., Xiang, H. and Jack, T. (1999) Generation of enhancer trap lines in Arabidopsis and characterization of expression patterns in the inflorescence. Plant J. 17, 699-707.

Candela, H., Martinez-Laborda, A. and Micol, J.L. (1999) Venation pattern formation in Arabidopsis thaliana vegetative leaves. Dev. Biol. 205, 205-216.

Cardon, G., Hohmann, S., Klein, J., Nettesheim, K., Saedler, H. and Huijser, P. (1999) Molecular characterisation of the Arabidopsis SBP-box genes. Gene, 237, 91-104.

Chae, H.J., Ke, N., Kim, H.R., Chen, S., Godzik, A., Dickman, M. and Reed, J.C. (2003) Evolutionarily conserved cytoprotection provided by Bax Inhibitor- 1 homologs from animals, plants, and yeast. Gene, 323, 101-113.

Chen, L. (1999) Combinatorial gene regulation by eukaryotic transcription factors. Curr. Opin. Struct. Biol. 9, 48-55.

Chen, B.S. and Hampsey, M. (2002) Transcription activation: unveiling the essential nature of TFIID. Curr. Biol. 12, R620-R622.

Clarke, J.H., Tack, D., Findlay, K., Van Montagu, M. and Van Lijsebettens, M. (1999) The SERRATE locus controls the formation of the early juvenile leaves and phase length in Arabidopsis. Plant $J$. 20, 493-501.

Clough, S.J. and Bent, A.F. (1998) Floral dip: a simplified method for Agrobacterium-mediated transformation of Arabidopsis thaliana. Plant J. 16, 735-743.

Cutler, S.R., Ehrhardt, D.W., Griffitts, J.S. and Somerville, C.R. (2000) Random GFP:::cDNA fusions enable visualization of subcellular structures in cells of Arabidopsis at a high frequency. Proc. Natl Acad. Sci. USA, 97, 3718-3723.

Dechend, R., Hirano, F., Lehmann, K., Heissmeyer, V., Ansieau, S., Wulczyn, F.G., Scheidereit, C. and Leutz, A. (1999) The Bcl-3 oncoprotein acts as a bridging factor between NF-kappaB/Rel and nuclear co-regulators. Oncogene, 18, 3316-3323.

Demura, T., Tashiro, G., Horiguchi, G. et al. (2002) Visualization by comprehensive microarray analysis of gene expression programs during transdifferentiation of mesophyll cells into xylem cells. Proc. Natl Acad. Sci. USA, 99, 15794-15799.

Desai, K., Sullards, M.C., Allegood, J., Wang, E., Schmelz, E.M., Hartl, M., Humpf, H.U., Liotta, D.C., Peng, Q. and Merrill, A.H., (2002) Fumonisins and fumonisin analogs as inhibitors of ceramide synthase and inducers of apoptosis. Biochim. Biophys. Acta, 1585, 188-192.

Dickman, M.B., Park, Y.K., Oltersdorf, T., Li, W., Clemente, T. and French, R. (2001) Abrogation of disease development in plants expressing animal antiapoptotic genes. Proc. Natl Acad. Sci. USA, 98, 6957-6962.

Dietrich, R.A., Richberg, M.H., Schmidt, R., Dean, C. and Dangl, J.L. (1997) A novel zinc finger protein is encoded by the Arabidopsis LSD1 gene and functions as a negative regulator of plant cell death. Cell, 88, 685-694.

Ely, K.R. and Kodandapani, R. (1998) Ankyrin(g) ETS domains to DNA. Nat. Struct. Biol. 5, 255-259.

Fukuda, H. (2000) Programmed cell death of tracheary elements as a paradigm in plants. Plant Mol. Biol. 44, 245-253. 
Genoud, T., Buchala, A.J., Chua, N.H. and Metraux, J.P. (2002) Phytochrome signalling modulates the SA-perceptive pathway in Arabidopsis. Plant J. 31, 87-95.

Gilchrist, D.G. (1998) Programmed cell death in plant disease: the purpose and promise of cellular suicide. Annu. Rev. Phytopathol. 36, 393-414

Goodin, M.M., Dietzgen, R.G., Schichnes, D., Ruzin, S. and Jackson, A.0. (2002) pGD vectors: versatile tools for the expression of green and red fluorescent protein fusions in agroinfiltrated plant leaves. Plant J. 31, 375-383.

Gray, J., Janick-Buckner, D., Buckner, B., Close, P.S. and Johal, G.S. (2002) Light-dependent death of maize I/s 1 cells is mediated by mature chloroplasts. Plant Physiol. 130, 1894-1907.

Groover, A. and Jones, A.M. (1999) Tracheary element differentiation uses a novel mechanism coordinating programmed cell death and secondary cell wall synthesis. Plant Physiol. 119, 375384.

Heery, D.M., Kalkhoven, E., Hoare, S. and Parker, M.G. (1997) A signature motif in transcriptional co-activators mediates binding to nuclear receptors. Nature, 387, 733-736.

Hiratsu, K., Ohta, M., Matsui, K. and Ohme-Takagi, M. (2002) The SUPERMAN protein is an active repressor whose carboxy-terminal repression domain is required for the development of normal flowers. FEBS Lett. 514, 351-354.

Hiratsu, K., Matsui, K., Koyama, T. and Ohme-Takagi, M. (2003) Dominant repression of target genes by chimeric repressors that include the EAR motif, a repression domain, in Arabidopsis. Plant J. 34, 733-739.

Jefferson, R.A. (1987) Assaying chimeric genes in plants: the GUS gene fusion system. Plant Mol. Biol. Rep. 5, 387-405.

Jinn, T.L., Stone, J.M. and Walker, J.C. (2000) HAESA, an Arabidopsis leucine-rich repeat receptor kinase, controls floral organ abscission. Genes Dev. 14, 108-117.

Kawai-Yamada, M., Jin, L., Yoshinaga, K., Hirata, A. and Uchimiya, H. (2001) Mammalian Bax-induced plant cell death can be downregulated by overexpression of Arabidopsis Bax Inhibitor-1 (AtBI1). Proc. Natl Acad. Sci. USA, 98, 12295-12300.

Klein, J., Saedler, H. and Huijser, P. (1996) A new family of DNA binding proteins includes putative transcriptional regulators of the Antirrhinum majus floral meristem identity gene SQUAMOSA. Mol. Gen. Genet. 250, 7-16.

Lacomme, C. and Santa Cruz, S. (1999) Bax-induced cell death in tobacco is similar to the hypersensitive response. Proc. Natl Acad. Sci. USA, 96, 7956-7961.

Laemmli, U. (1970) Cleavage of structural proteins during the assembly of the head of bacteriophage T4. Nature, 227, 680685.

Laity, J.H., Lee, B.M. and Wright, P.E. (2001) Zinc finger proteins: new insights into structural and functional diversity. Curr. Opin. Struct. Biol. 11, 39-46.

Liang, H., Yao, N., Song, J.T., Luo, S., Lu, H. and Greenberg, J.T. (2003) Ceramides modulate programmed cell death in plants. Genes Dev. 17, 2636-2641.

Lincoln, J.E., Richael, C., Overduin, B., Smith, K., Bostock, R. and Gilchrist, D.G. (2002) Expression of the antiapoptotic baculovirus p35 gene in tomato blocks programmed cell death and provides broad-spectrum resistance to disease. Proc. Natl Acad. Sci. USA, 99, 15217-15221.

Liu, Y.G., Mitsukawa, N., Oosumi, T. and Whittier, R.F. (1995) Efficient isolation and mapping of Arabidopsis thaliana T-DNA insert junctions by thermal asymmetric interlaced PCR. Plant J. 8, 457463.

Liu, G., Xia, T. and Chen, X. (2003) The activation domains, the proline-rich domain, and the $\mathrm{C}$-terminal basic domain in p53 are necessary for acetylation of histones on the proximal p21 promoter and interaction with p300/CREB-binding protein. J. Biol. Chem. 278, 17557-17565.

Lu, H., Rate, D.N., Song, J.T. and Greenberg, J.T. (2003) ACD6, a novel ankyrin protein, is a regulator and an effector of salicylic acid signaling in the Arabidopsis defense response. Plant Cell, 15, 2408-2420.

Mach, J.M., Castillo, A.R., Hoogstraten, R. and Greenberg, J.T. (2001) The Arabidopsis-accelerated cell death gene ACD2 encodes red chlorophyll catabolite reductase and suppresses the spread of disease symptoms. Proc. Natl Acad. Sci. USA, 98, 771-776.

Mao, C., Xu, R., Bielawska, A. and Obeid, L.M. (2000) Cloning of an alkaline ceramidase from Saccharomyces cerevisiae. An enzyme with reverse (CoA-independent) ceramide synthase activity. J. Biol. Chem. 275, 6876-6884.

Massari, M.E. and Murre, C. (2000) Helix-loop-helix proteins: regulators of transcription in eucaryotic organisms. Mol. Cell. Biol. 20, 429-440.

Messenguy, F. and Dubois, E. (2003) Role of MADS box proteins and their cofactors in combinatorial control of gene expression and cell development. Gene, 316, 1-21.

Morelli, G. and Ruberti, I. (2002) Light and shade in the photocontrol of Arabidopsis growth. Trends Plant Sci. 7, 399-404.

Moreno, M.A., Harper, L.C., Krueger, R.W., Dellaporta, S.L. and Freeling, M. (1997) liguleless 1 encodes a nuclear-localized protein required for induction of ligules and auricles during maize leaf organogenesis. Genes Dev. 11, 616-628.

Niggeweg, R., Thurow, C., Weigel, R., Pfitzner, U. and Gatz, C. (2000) Tobacco TGA factors differ with respect to interaction with NPR1, activation potential and DNA-binding properties. Plant Mol. Biol. 42, 775-788.

Ohno, C.K., Reddy, G.V., Heisler, M.G. and Meyerowitz, E.M. (2004) The Arabidopsis JAGGED gene encodes a zinc finger protein that promotes leaf tissue development. Development, 131, 1111-1122.

Ohta, M., Matsui, K., Hiratsu, K., Shinshi, H. and Ohme-Takagi, M. (2001) Repression domains of class II ERF transcriptional repressors share an essential motif for active repression. Plant Cell, 13, 1959-1968.

Poethig, R.S. (2003) Phase change and the regulation of developmental timing in plants. Science, 301, 334-336.

Prado, F., Vicent, G., Cardalda, C. and Beato, M. (2002) Differential role of the proline-rich domain of nuclear factor 1-C splice variants in DNA binding and transactivation. J. Biol. Chem. 277, 16383-16390.

Prigge, M.J. and Wagner, D.R. (2001) The Arabidopsis SERRATE gene encodes a zinc-finger protein required for normal shoot development. Plant Cell, 13, 1263-1279.

Pruzinska, A., Tanner, G., Anders, I., Roca, M. and Hortensteiner, S. (2003) Chlorophyll breakdown: pheophorbide a oxygenase is a Rieske-type iron-sulfur protein, encoded by the accelerated cell death 1 gene. Proc. Natl Acad. Sci. USA, 100, 15259-15264.

Rate, D.N., Cuenca, J.V., Bowman, G.R., Guttman, D.S. and Greenberg, J.T. (1999) The gain-of-function Arabidopsis acd6 mutant reveals novel regulation and function of the salicylic acid signaling pathway in controlling cell death, defense, and cell growth. Plant Cell, 11, 1695-1708.

Richael, C., Lincoln, J.E., Bostock, R.M. and Gilchrist, D.G. (2001) Caspase inhibitors reduce symptom development and limit bacterial proliferation in susceptible plant tissues. Physiol. Mol. Plant Pathol. 59, 213-221.

Riechmann, J.L., Heard, J., Martin, G. et al. (2000) Arabidopsis transcription factors: genome-wide comparative analysis among eukaryotes. Science, 290, 2105-2110. 
Robbins, J., Dilworth, S.M., Laskey, R.A. and Dingwall, C. (1991) Two interdependent basic domains in nucleoplasmin nuclear targeting sequence: identification of a class of bipartite nuclear targeting sequence. Cell, 64, 615-623.

Sambrook, J. and Russell, D.W. (2001) Molecular Cloning: $A$ Laboratory Manual, 3rd edn. Cold Spring Harbor, New York: Cold Spring Harbor Laboratory Press.

Schob, H., Kunz, C. and Meins, Jr, F. (1997) Silencing of transgenes introduced into leaves by agroinfiltration: a simple, rapid method for investigating sequence requirements for gene silencing. Mol. Gen. Genet. 256, 581-585.

Stone, J.M., Heard, J.E., Asai, T. and Ausubel, F.M. (2000) Simulation of fungal-mediated cell death by fumonisin B1 and selection of fumonisin B1-resistant ( $f b r)$ Arabidopsis mutants. Plant Cell, $12,1811-1822$.

Tan, S. and Richmond, T.J. (1998) Eukaryotic transcription factors. Curr. Opin. Struct. Biol. 8, 41-48.

Tiwari, S.B., Hagen, G. and Guilfoyle, T.J. (2004) Aux/IAA proteins contain a potent transcriptional repression domain. Plant Cell, 16, 533-543.

Tolleson, W.H., Couch, L.H., Melchior, Jr, W.B., Jenkins, G.R., Muskhelishvili, M., Muskhelishvili, L., McGarrity, L.J., Domon, O., Morris, S.M. and Howard, P.C. (1999) Fumonisin B1 induces apoptosis in cultured human keratinocytes through sphinganine accumulation and ceramide depletion. Int. J. Oncol. 14, 833-843.

Tsukaya, H., Shoda, K., Kim, G.T. and Uchimiya, H. (2000) Heteroblasty in Arabidopsis thaliana (L.) Heynh. Planta, 210, 536-542.
Tsukaya, H., Kozuka, T. and Kim, G.T. (2002) Genetic control of petiole length in Arabidopsis thaliana. Plant Cell. Physiol. 43 1221-1228.

Unte, U.S., Sorensen, A.M., Pesaresi, P., Gandikota, M., Leister, D., Saedler, H. and Huijser, P. (2003) SPL8, an SBP-box gene that affects pollen sac development in Arabidopsis. Plant Cell, 15, 1009-1019.

Vanacker, H., Lu, H., Rate, D.N. and Greenberg, J.T. (2001) A role for salicylic acid and NPR1 in regulating cell growth in Arabidopsis. Plant J. 28, 209-216.

Wang, W., Jones, C., Ciacci-Zanella, J., Holt, T., Gilchrist, D.G. and Dickman, M.B. (1996) Fumonisins and Alternaria alternata ly copersici toxins: sphinganine analog mycotoxins induce apoptosis in monkey kidney cells. Proc. Natl Acad. Sci. USA, 93, 3461-3465.

Yamasaki, K., Kigawa, T., Inoue, M. et al. (2004) A novel zinc-binding motif revealed by solution structures of DNA-binding domains of Arabidopsis SBP-family transcription factors. J. Mol. Biol. 337, 49-63.

Yang, Y., Li, R. and Qi, M. (2000) In vivo analysis of plant promoters and transcription factors by agroinfiltration of tobacco leaves. Plant J. 22, 543-551.

Yang, M., Wardzala, E., Johal, G.S. and Gray, J. (2004) The woundinducible L/s1 gene from maize is an orthologue of the Arabidopsis Acd1 gene, and the LLS1 protein is present in non-photosynthetic tissues. Plant Mol. Biol. 54, 175-191. 


\title{
Identification of a Consensus DNA-Binding Site for the Arabidopsis thaliana SBP Domain Transcription Factor, AtSPL14, and Binding Kinetics by Surface Plasmon Resonance $^{\dagger}$
}

\author{
Xinwen Liang, Tara J. Nazarenus, and Julie M. Stone* \\ Department of Biochemistry, Plant Science Initiative, Redox Biology Center, University of Nebraska, Lincoln, Nebraska 68588
}

Received July 20, 2007; Revised Manuscript Received January 8, 2008

\begin{abstract}
Proteins with a conserved Cys- and His-rich SQUAMOSA promoter binding protein (SBP) domain are transcription factors restricted to photosynthetic organisms that possess a novel two Zn-finger structure DNA-binding domain. Despite the fact that altered expression of some SBP-encoding genes has profound effects on organism growth and development, little is known about SBP domain protein target genes. Misexpression of the Arabidopsis thaliana AtSPL14 SBP domain gene confers resistance to programmed cell death and modifies plant architecture. A consensus DNA-binding motif for AtSPL14 was identified by systematic evolution of ligands by exponential enrichment (SELEX) or random binding site selection (RBSS). DNA recognized by AtSPL14 contained the core binding motif (GTAC) found for other SBP domain proteins, but mutational analyses indicated that at least one additional flanking nucleotide is necessary for effective AtSPL14-DNA interaction. Comparison of several SBP domain amino acid sequences allows us to hypothesize which specific amino acids might participate in this sequence-specific DNA recognition. Electrophoretic mobility shift assays (EMSA) with mutant AtSPL14 DNA-binding domain proteins indicated that not all of the $\mathrm{Zn}^{2+}$ ion coordinating ligands in the second $\mathrm{Zn}$ structure are strictly required for DNA binding. Surface plasmon resonance (SPR) was used to evaluate AtSPL14 in vitro binding kinetics for comparison of equilibrium binding constants with other SBP domain proteins. These data provide a strong basis for further experiments aimed at defining and distinguishing the sets of genes regulated by the closely related SBP domain family members.
\end{abstract}

Proper growth and development of multicellular organisms depend on a delicate balance between cell proliferation and programmed cell death (PCD). ${ }^{1}$ In plants, PCD is required for tracheary element differentiation to form the waterconducting xylem tissue and accurate formation of various reproductive organs $(1-5)$. PCD is also an important aspect of plant defense against pathogen attack (6-8). Despite the essential nature of PCD, large gaps remain in our knowledge of the mechanistic details and molecular components controlling plant PCD. Therefore, to identify novel genes that might participate in plant PCD, we developed a mutant selection scheme for the model plant Arabidopsis thaliana using a PCD-inducing fungal toxin fumonisin B1 (FB1), to identify FB1-resistant ( $f b r$ ) mutants (9-11). Misexpression of the AtSPL14 gene in the fbr6 mutant confers the ability to proliferate in the presence of FB1 and modifies normal plant architecture, linking the insensitivity to cell death to altered plant development (9). AtSPL14 has features of a DNA-binding transcription factor, including a Cys- and Hisrich SQUAMOSA promoter binding protein (SBP) domain predicted to bind DNA, ankyrin repeats that mediate pro-

\footnotetext{
${ }^{\dagger}$ This research was supported by a grant from the Chemical Sciences, Geosciences and Biosciences Division, Office of Basic Energy Sciences, Office of Science, U.S. Department of Energy (DE-FG02-05ER15648) to J.M.S. and is a contribution of the Nebraska Agricultural Research Division.

* Address correspondence to this author. E-mail: jstone2@unl.edu. Phone: 402-472-4902. Fax: 402-472-3139.
}

tein-protein interactions, nuclear localization, and ability to bind to A. thaliana genomic DNA (9).

SBP domain proteins are defined by a conserved approximately 80 amino acid-protein domain (the SBP domain or SBP box) found only in proteins from photosynthetic organisms, ranging from single-celled algae (e.g., Chlamydomonas reinhardtii) to higher plants (e.g., A. thaliana and Oryza sativa). The SBP gene families are comprised of 16 genes in A. thaliana and 19 genes in $O$. sativa that encode proteins that share the highly conserved SBP DNA-binding domain but are diverse in overall domain structure $(12,13)$. To date, only a few functions for SBP domain proteins have been reported, perhaps due to genetic redundancy of closely related family members. In all cases, SBP domain proteins have been implicated in various aspects of plant growth and development, including metal sensing in algae and directing development of leaves, embryos, and floral organs in higher

\footnotetext{
${ }^{1}$ Abbreviations: CuRE, copper-responsive element; dsDNA, doublestranded DNA; DTT, dithiothreitol; EDTA, ethylenediaminetetraacetic acid; EMSA, electrophoretic mobility shift assay; FB1, fumonisin B1; $f b r$, FB1-resistant; HEPES, $N$-(2-hydroxyethyl)piperazine- $N$ '-2-ethanesulfonic acid; IPTG, isopropyl $\beta$-D-1-thiogalactopyranoside; NMR, nuclear magnetic resonance; PCD, programmed cell death; PMSF, phenylmethanesulfonyl fluoride; RBSS, random binding site selection; RU, resonance (response) units; SA, streptavidin; SBP, SQUAMOSA promoter binding protein; SDS, sodium dodecyl sulfate; SELEX, systematic evolution of ligands by exponential enrichment; SPL, SQUAMOSA promoter binding protein-like; SPR, surface plasmon resonance; WT, wild type.
} 
plants (9, 13-22). Some of these SBP domain proteins may also be posttranscriptionally regulated by noncoding microRNAs to control their spatial and temporal expression (23-25). Despite the obvious importance of these proteins, the specific genes targeted by individual SBP domain family members and the molecular consequences of their actions are largely unknown.

To fully understand the physiological functions of AtSPL14 in regulating plant PCD and/or development, AtSPL14 target genes, their modes of regulation, and the consequences of expression/repression need to be determined. As one step toward that goal, we used an affinity-based assay, referred to as systematic evolution of ligands by exponential enrichment (SELEX) or random binding site selection (RBSS) to screen a random pool of dsDNA fragments for sequences capable of binding to recombinant AtSPL14 protein. From this analysis, an AtSPL14-binding consensus DNA motif was derived. Mutational analyses indicated that predominantly the core motif, CGTAC, is essential for AtSPL14 protein binding to the DNA in vitro.

Recent structures of SBP domains determined by nuclear magnetic resonance (NMR) indicate that SBP domains form a unique two Zn-finger structure DNA-binding domain $(26,27)$. The SBP domain contains eight absolutely conserved Cys or His residues, some of which are critical for SBP domain DNA binding (28). We determined that all of the highly conserved cysteines in the two $\mathrm{Zn}^{2+}$ ion binding structures of the AtSPL14 SBP domain binding are important for DNA recognition by electrophoretic mobility shift assays (EMSA) and surface plasmon resonance (SPR). Yet, an AtSPL14 SBP domain with one of the Cys residues in the second Zn-finger structure mutated retained some DNA-binding ability. Moreover, we monitored the kinetic features of the AtSPL14 SBP domain-DNA binding by SPR. We further compare and contrast the target sequences and the equilibrium binding constants we determined for AtSPL14 with those of other SBP domain proteins $(18,28,29)$.

\section{MATERIALS AND METHODS}

Recombinant AtSPL14 Protein Expression and Purification. Two different truncated and epitope-tagged versions of recombinant AtSPL14 proteins were used. The full-length AtSPL14 cDNA was generated by reverse transcriptionpolymerase chain reaction (RT-PCR) from RNA isolated from ecotype Col-0 (the reference genotype for the A. thaliana genome) using oligonucleotide primers SBPF (5'-GGATCCATGGATGAGGTAGGAGCTCAAGTG-3') and SBPR (5'-ACTAGTCCGGATCCGATTGAGCCATAATCCAAACCTC-3') and verified by DNA sequencing (30). Engineered BamHI and existing internal SalI restriction enzyme recognition sites were used to subclone FBR6 short (FBR6s; aa 1-402) into BamHI/SalI-digested pET-28a(+) to produce a protein composed of an $\mathrm{N}$-terminal His tag, thrombin cleavage site, and T7 tag fused to a region of AtSPL14 encompassing the DNA-binding domain (Novagen, EMD Chemicals, Inc., Darmstadt, Germany). The His-tagged FBR6s protein was 447 amino acids with a predicted molecular mass of $48.8 \mathrm{kDa}$.

For electrophoretic mobility shift assays (EMSA) and surface plasmon resonance (SPR) binding assays, recombinant epitope-tagged FBR6 supershort (FBR6ss; aa 111-200) protein was used. The conserved SBP domain of AtSPL14 was amplified by PCR using oligonucleotide primers oJS86 (5'-CCGAATTCTCTCCGGGAGGGAATTATCCC-3') and oJS87 (5'-CCGAATTCTTATGCAACCTCCTCCGGCTGCG$\left.3^{\prime}\right)$ and verified by DNA sequencing (30). The resulting PCR product was subcloned into $\mathrm{pET}-28 \mathrm{a}(+)$ to produce a protein composed of an N-terminal His tag, thrombin cleavage site, and T7 tag fused to a region of AtSPL14 encompassing the DNA-binding domain. The His-tagged FBR6ss protein was 126 amino acids with a predicted molecular mass of 14.3 $\mathrm{kDa}$.

The recombinant proteins were expressed in Escherichia coli by inducing log phase cultures with $0.2 \mathrm{mM}$ isopropyl $\beta$-D-1-thiogalactopyranoside (IPTG) at $37{ }^{\circ} \mathrm{C}$ for $2 \mathrm{~h}$, and proteins were purified on $\mathrm{Ni}^{2+}$-conjugated affinity resin according to the manufacturer's instructions (ProBond Purification System; Invitrogen, Carlsbad, CA). For SELEX experiments proteins were retained on the resin.

Site-Directed Mutagenesis. The site-directed mutagenesis was performed according to the Stratagene's QuickChange site-directed mutagenesis kit instruction manual (Stratagene, Cedar Creek, TX). Oligonucleotide primers used to mutate the nucleotides in the AtSPL14-binding DNA and the cysteine residues of the AtSPL14 SBP domain are shown in Tables S1 and S2 of the Supporting Information, respectively.

Systematic Evolution of Ligands by Exponential Enrichment (SELEX) or Random Binding Site Selection (RBSS). A random pool of oligonucleotides (76 nucleotides) of sequence 5'-GCTGCAGTTGCACTGAATTCGCCTCN ${ }_{26}$ CGACAGGATCCGCTGAACTGACCTG- ${ }^{\prime}$, where $\mathrm{N}_{26}$ represents 26 randomized nucleotides, was synthesized by equimolar incorporation of $\mathrm{A}, \mathrm{G}, \mathrm{C}$, and $\mathrm{T}$ at each " $\mathrm{N}$ " position (Integrated DNA Technologies, Coralville, IA). The two sets of 25 nucleotides flanking the 26-nucleotide random core were designed for amplification by PCR. To make doublestranded DNA (dsDNA), the random pool of oligonucleotides (100 ng) was subjected to PCR using the forward primer and Taq polymerase enzyme (94, 68, and $72{ }^{\circ} \mathrm{C}, 1$ cycle), and the PCR products were purified by agarose gel electrophoresis $(1.5 \%$ MetaPhor agarose; Cambrex Bio Science Rockland, Inc., Rockland, ME) to yield ds-R76, the substrate in the initial binding reaction.

The binding reactions were carried out on ice essentially as described with a few modifications (31). The recombinant protein T7-His 6 -FBR6s was purified using a His tag purification kit (ProBond; Invitrogen, Carlsbad, CA) and retained on the resin. The resin with immobilized protein $(200 \mu \mathrm{L})$ was washed twice with binding buffer $(20 \mathrm{mM}$ Tris- $\mathrm{HCl}$, pH 7.6, $50 \mathrm{mM} \mathrm{NaCl}, 1 \mathrm{mM} \mathrm{MgCl} 2,0.2 \mathrm{mM}$ EDTA, $5 \%$ glycerol, $0.5 \mathrm{mM}$ DTT, $50 \mu \mathrm{M}$ PMSF), mixed with $50 \mu \mathrm{g} /$ $\mathrm{mL}$ poly(dIdC) (Amersham Biosciences, Cleveland, $\mathrm{OH}$ ) to reduce nonspecific binding for $10 \mathrm{~min}$, and incubated with ds-R76 DNA (200 ng) for $60 \mathrm{~min}$, with gentle tapping every $10 \mathrm{~min}$. The immobilized protein-DNA complexes were washed with TN buffer (10 mM Tris- $\mathrm{HCl}, \mathrm{pH} 7.4,150 \mathrm{mM}$ $\mathrm{NaCl}$ ) five times, and the DNA was eluted with $200 \mu \mathrm{L}$ of dissociation buffer (0.5 M Tris-HCl, pH 7.4, 20 mM EDTA, $10 \mathrm{mM} \mathrm{NaCl}, 0.2 \%$ SDS). The bound DNA was amplified by PCR using $250 \mathrm{nM}$ oligonucleotide primers that anneal to the defined terminal sequences of the 76-nucleotide oligonucleotide for 20 cycles. The resulting product was used as the substrate in the second round of SELEX. After five 
serial selection rounds, the amplified DNA was cloned into vector pGEM-TEasy (Promega, Madison, WI) and subjected to DNA sequencing (University of Nebraska-Lincoln, Genomics Core Facility). Effective DNA binding was verified by electrophoretic mobility shift assay (EMSA) competition assays.

Electrophoretic Mobility Shift Assay (EMSA). DNA fragments were fluorescently labeled by PCR amplification in a reaction containing $100 \mu \mathrm{M}$ dNTPs, $1 \times$ PCR buffer, $1.5 \mathrm{mM}$ $\mathrm{MgCl}_{2}, 2 \mathrm{ng}$ of DNA template (pGEM-TEasy subclones selected from SELEX), $300 \mathrm{nM}$ 5'-IR-dye 700 GTACCTTCGTTGCCGCTAG- $3^{\prime}$ corresponding to the T7 promoter (Li-Cor, Lincoln, NE), $300 \mathrm{nM}$ primer R or primer F, and Taq polymerase enzyme. The resulting PCR product was quantified using gel electrophoresis. Electrophoretic mobility shift assay binding reactions were performed in the same binding buffer used in the SELEX (exception: $1 \mathrm{mM}$ DTT and no PMSF) in a total volume of $20 \mu \mathrm{L}$ containing $60 \mathrm{nM}$ protein and $4 \mathrm{nM}$ labeled DNA and incubated for $30 \mathrm{~min}$ at $25^{\circ} \mathrm{C}$ in darkness prior to electrophoresis. The protein-DNA binding mixture was electrophoretically resolved for $45 \mathrm{~min}$ at $4{ }^{\circ} \mathrm{C}$ in the dark on a prerun $8 \%$ nondenaturing polyacrylamide gel (polyacrylamide-bis ratio $=37.5: 1$ ) in Tris - borateEDTA buffer ( $89 \mathrm{mM}$ Tris, $89 \mathrm{mM}$ boric acid, and $2.5 \mathrm{mM}$ EDTA) at constant voltage $(15 \mathrm{~V} / \mathrm{cm})$. Gels were analyzed using an Odyssey Infrared Imager (Li-Cor, Lincoln, NE).

Immobilization of Biotinylated DNA on the SA Sensor Chip. Cognate and noncognate DNA fragments (156 bp) containing dsR76 used in the SELEX experiments were biotinylated by PCR amplification with dsDNA cloned in pGEM-TEasy as templates, 5'-biotin-GTACCTTCGTTGCCGCTAG-3' oligonucleotide corresponding to the T7 promoter (IDTDNA, Cedar Rapids, IA), and either primer R or primer F. The PCR products were purified by the QIAquick PCR purification kit (Qiagen, Valencia, CA), and DNA was immobilized on streptavidin (SA) sensor chips (Biacore AB, Uppsala, Sweden).

5'-Biotin-labeled DNA (the random binding site selected DNA 14 containing the consensus FBR6ss binding site, CCGTAC, Figure 1) was immobilized onto the SA sensor chip surface [450 resonance (response) units, RU] to provide the maximal level of RU associated with protein binding in the range of 50-100 RU. SA chips were conditioned with three consecutive $1 \mathrm{~min}$ injections of $1 \mathrm{M} \mathrm{NaCl}$ and $50 \mathrm{mM}$ $\mathrm{NaOH}$ prior to immobilization. Two reference cells were used as controls for background subtraction: reference 1 was the surface alone (no bound DNA), and reference 2 had a noncognate DNA (a random DNA that did not possess the consensus binding motif) immobilized to the reference cell at the same concentration as the cognate DNA.

Surface Plasmon Resonance (SPR) Analysis. The purified His-FBR6ss protein was desalted and equilibrated in HBSEP buffer using Centricon-mediated centrifugal filtration (10 kDa cutoff; Millipore, Billerica, MA). The protein was diluted in HBS-EP buffer to yield several different concentrations ranging from 3.25 to $300 \mathrm{nM}$. Varying protein concentrations were injected at a $75 \mu \mathrm{L} / \mathrm{min}$ flow rate. The chip surface was regenerated by injection of $0.1 \%$ SDS and $3 \mathrm{mM}$ EDTA buffer for $1 \mathrm{~min}$ after each protein injection. Responses from the reference cell(s) were subtracted to correct for refractive index changes and nonspecific binding.
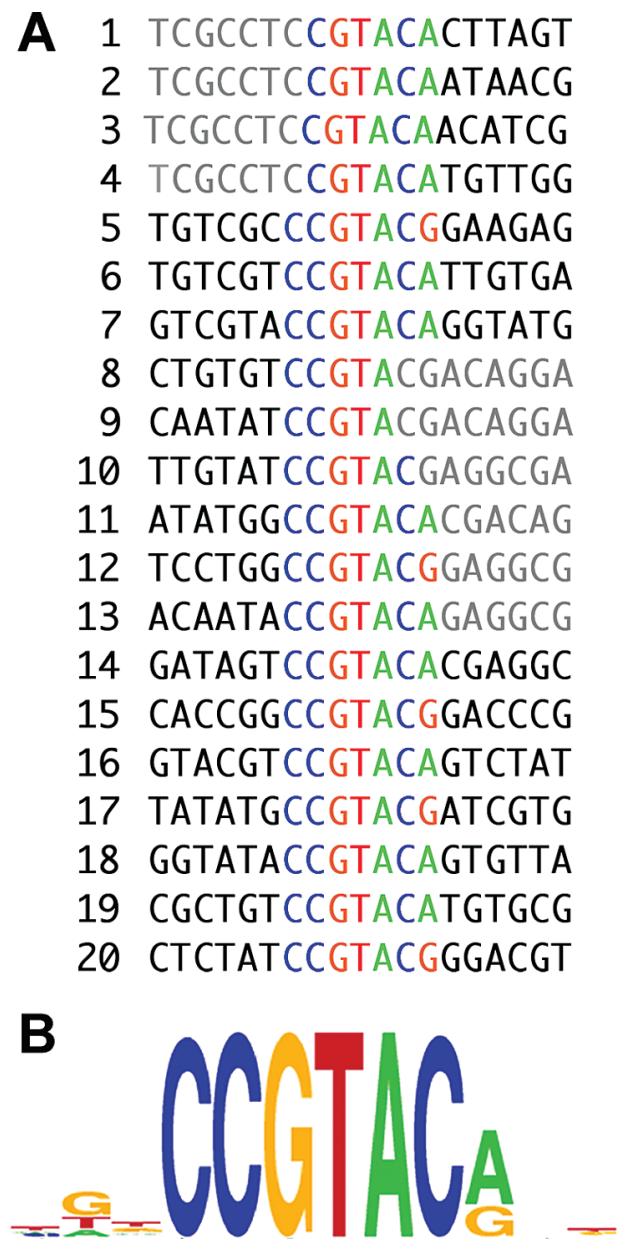

FIGURE 1: The consensus target site for the AtSPL14 SBP DNAbinding domain determined by SELEX. Double-stranded DNA molecules containing a 26-nucleotide completely randomized central region were subjected to repetitive cycles of binding to recombinant AtSPL14 bound to a $\mathrm{Ni}^{2+}$-chelating affinity resin and PCR amplification. The individual binders were subsequently tested by electrophoretic mobility shift assays (EMSA) and competition with unlabeled probe (as in Figure 2A), yielding 20 distinct dsDNA fragments capable of binding to the AtSPL14 SBP domain. (A) An alignment of the 20 individual binders based on the results of the web-based multiple expectation maximization for motif elicitation (MEME) analysis program (36). The core consensus sequence nucleotides are in color, the adjacent random nucleotides are in black, and the nonrandom nucleotides derived from the fixed sequence immediately flanking the random nucleotides in the dsDNA pool are in gray. (B) A representation of the consensus DNA target binding motif (disregarding the fixed nucleotides flanking the random core) using WebLogo (37). The degree of conservation is indicated by the height of the letters. The core sequence "CCGTAC" was found in all dsDNA-binding fragments.

SPR Data Analysis. Data were analyzed with BIAevaluation 3.0 software (Biacore, Piscataway, NJ), which automatically calculates binding parameters taking into account control and experimental results allowing for quantitative kinetic analyses. Association $\left(k_{\mathrm{a}}\right)$ and dissociation $\left(k_{\mathrm{d}}\right)$ rates and overall affinity, the equilibrium dissociation constant $\left(K_{\mathrm{D}}\right)$, were calculated using a simple bimolecular 1:1 Langmuir isotherm binding model $(\mathrm{A}+\mathrm{B} \leftrightarrow \mathrm{A}-\mathrm{B})$ and a mass transfer model that accounts for mass transfer limitations due to rapid association and/or dissociation rates (32). Nonspecific binding effects were subtracted using the sensorgram generated from the control reference cell(s). Experiments were replicated in triplicate with similar results. 
A

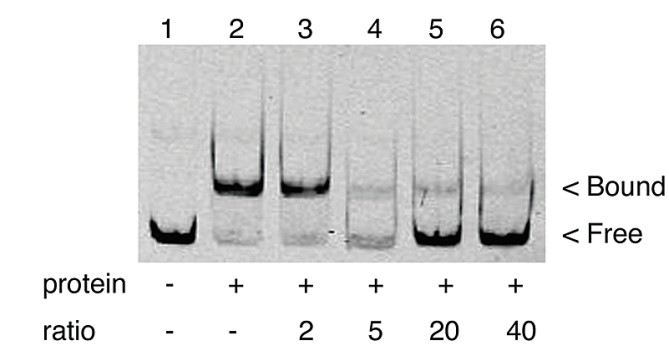

B wt TCGCCTCCGTACACTTAGT

M1 .............

M2 $\ldots \ldots$ T. . . . . . .

M3 $\ldots \ldots . . \ldots \ldots \ldots$

M4 $\ldots \ldots$.........

M5 $\quad \ldots \ldots \ldots$. . . . . . . .

M6 $\ldots \ldots$. T. . . . .

M7 ............

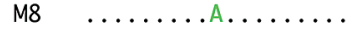

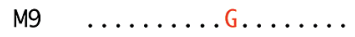

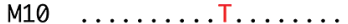

$\mathrm{M} 11 \quad \ldots \ldots \ldots . \mathrm{T} \ldots \ldots$.

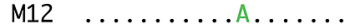

M13 ..............
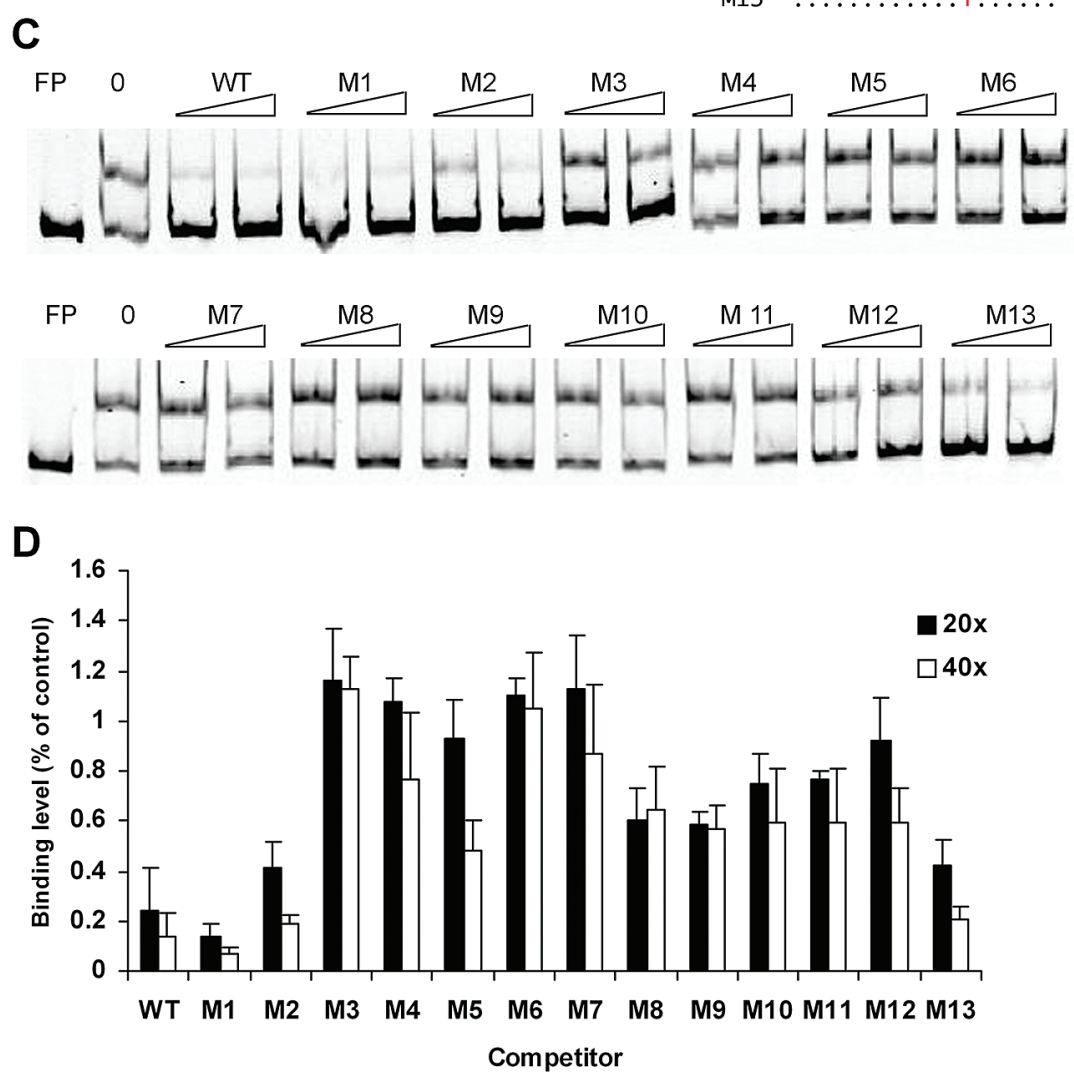

FIGURE 2: Specific AtSPL14 DNA binding by electrophoretic mobility shift assays (EMSA) and competition assays. (A) An example of the initial competition assays by EMSA used to determine binding of the individual dsDNA fragments identified by SELEX. The doublestranded DNA probe was generated by PCR with IRDye 700 fluorescently labeled (probe) or unlabeled (competitor) oligonucleotide primers. The probe $(4 \mathrm{nM})$ was incubated without $(-)$ or with $(+)$ recombinant His-tagged AtSPL14 SBP domain protein (FBR6ss, 60 nM). For testing specificity, increasing amounts of unlabeled competitor were included in the binding reaction; the ratio of competitor:probe is indicated. "Complexes" were separated on an $8 \%$ nondenaturing polyacrylamide gel and visualized by infrared imaging. Lanes: (1) free probe; (2) probe plus AtSPL14 SBP domain protein; (3-6) probe plus increasing amounts of unlabeled competitor. (B) For EMSA competition assays, single nucleotide substitutions in the core consensus binding site of a selected dsDNA-binding fragment were generated by sitedirected mutagenesis. The core consensus motif is in color with flanking nucleotides in black for the wild-type (wt) dsDNA, and individual nucleotide changes for the mutated (M1-M13) dsDNA are indicated. (C) EMSA competition assays with the wild-type (WT) or mutated (M1-M13) dsDNA fragments. For the binding reactions, "FP" indicates free probe with no protein, "0" indicates no competitor, and the triangles represent increasing amount of competitor in the binding reaction $(20 \times$ or $40 \times$ molar ratios). (D) Band intensities corresponding to bound complexes were determined by infrared imaging (Odyssey; Li-Cor, Lincoln, NE). Binding efficiencies were normalized to a control binding reaction with no competitor on each gel ("0" in panel C). Binding levels with a $20 \times$ molar ratio (black bars) and a $40 \times$ molar ratio (white bars) of unlabeled competitor are shown. Error bars represent $95 \%$ confidence levels from experiments performed in triplicate.

\section{RESULTS}

Identification of a Consensus Binding Site for the AtSPL14 SBP Domain by Systematic Evolution of Ligands by Exponential Enrichment (SELEX). SELEX or random binding site selection (RBSS), an in vitro oligonucleotide binding and PCR amplification method, was used to define consensus DNA-binding sequences for the AtSPL14 SBP DNA-binding domain (33-35). The AtSPL14-binding DNA was selected from a pool of $76 \mathrm{bp}$ of double-stranded DNA (dsDNA) with a central core of 26 random nucleotides by repeated cycles of binding to the hexahistidine-tagged FBR6s protein (encompassing the SBP DNA-binding domain) immobilized on $\mathrm{Ni}^{2+}$-chelating affinity resin. Fifty-seven individual clones that were derived from five serial rounds of selection were subcloned and subjected to DNA sequencing, revealing that identical clones were identified multiple times. All of the unique clones were tested for binding to FBR6ss using EMSA assays and competition with unlabeled dsDNA probe. 

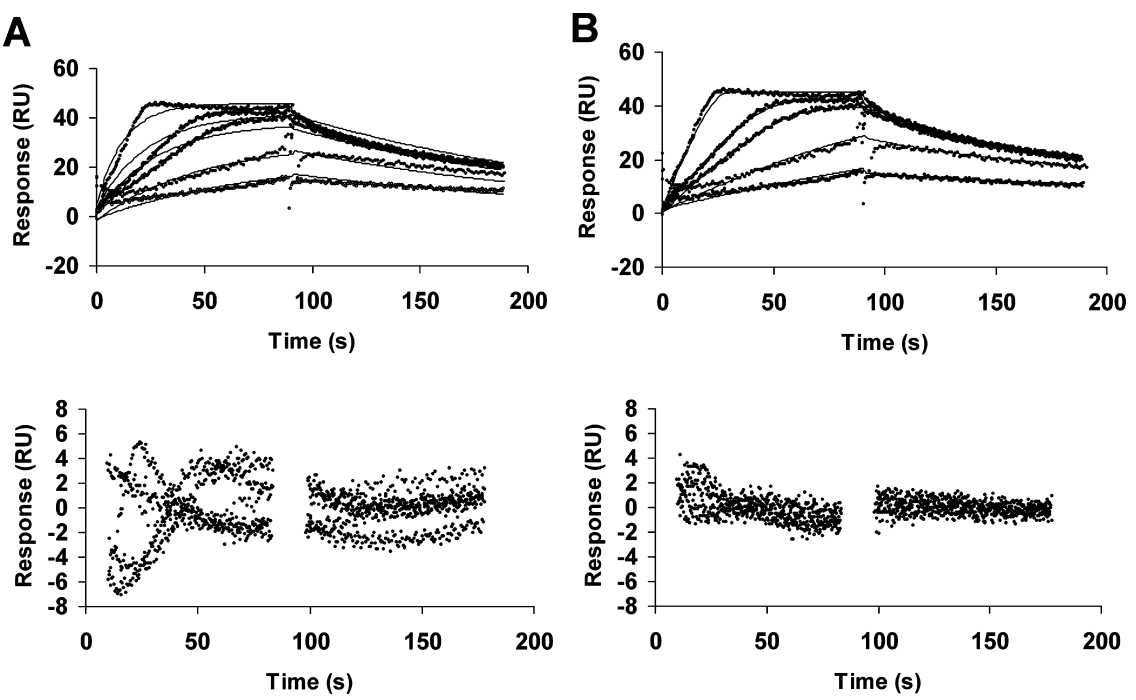

FIGURE 3: Global analysis of SPR biosensor data for AtSPL14 SBP domain protein-DNA interaction kinetic analyses. Top panels: The dotted lines represent SPR sensorgrams (resonance units, RU) obtained by injecting different concentrations of the AtSPL14 SBP domain protein $(5,15,20,25,30$, and $50 \mathrm{nM}$; bottom to top) onto a SA sensor chip coated with a representative 156 bp cognate dsDNA fragment identified by SELEX that bound in EMSA competition assays. Binding data were collected at a flow rate of $75 \mu \mathrm{L} / \mathrm{min}$. Signals from the control reference cell (coated with a noncognate DNA) were subtracted. Bottom panels: Residual plot showing the difference between measured and calculated responses. (A) Best fits of the binding data to a simple bimolecular 1:1 Langmuir binding model are represented by solid black lines.A residual plot showing the difference between measured and calculated responses indicated that the 1:1 Langmuir binding model is not a good fit $( \pm 10 \mathrm{RU})$. (B) Best fits of the binding data to a simple bimolecular 1:1 mass transfer binding model are represented by solid black lines. A residual plot showing the difference between measured and calculated responses indicated that the 1:1 mass transfer binding model is a good fit ( $\pm 3 \mathrm{RU})$. Kinetic binding constants were determined for the mass transfer binding model: the association rate constant $k_{\mathrm{a}}=2.5 \times 10^{7} \mathrm{M}^{-1} \mathrm{~s}^{-1}$, the dissociation rate constant $k_{\mathrm{d}}=7.4 \times 10^{-2} \mathrm{~s}^{-1}$, and the equilibrium binding constant $K_{\mathrm{A}}=k_{\mathrm{a}} / k_{\mathrm{d}}=3.3 \times 10^{8} \mathrm{M}^{-1}$.

The final outcome of these analyses was 20 individual sequences. The consensus binding site was identified using the web-based multiple expectation maximization for motif elicitation (MEME) analysis program with manual manipulation to optimize the output and is represented using WebLogo $(36,37)$.

Alignment of the 20 unique sequences indicated CCGTAC(A/G) as the optimal binding site for the AtSPL14 SBP domain (Figure 1). Nucleotides of the core consensus binding motif in a selected individual SBP domain binder (14 in Figure 1A) were mutated to several different nucleotides (Figure 2B). The wild-type (WT) and mutant (M1-M13) DNAs were then tested for binding to FBR6ss in EMSA competition assays. These experiments revealed that the $\mathrm{C}$ in position 1 and the $\mathrm{A}$ or $\mathrm{G}$ in position 7 are dispensable for binding, as dsDNA fragments with mutations in these nucleotides could still effectively compete in EMSA competition assays (Figure 2). Positions 2, 3, and 4 (CGT) are critical for DNA binding, and even conservative changes (i.e., pyrimidine-to-pyrimidine changes in the $\mathrm{C}$ and $\mathrm{T}$ ) effectively abolished the ability of these mutated dsDNAs to compete for binding. Mutation of the $\mathrm{A}$ and $\mathrm{C}$ in positions 5 and 6 indicated that these nucleotides are also important, as they markedly reduced competition for AtSPL14 SBP domain binding (Figure 2). These mutational analyses support that the AtSPL14 SBP domain recognizes a core consensus binding motif of CGTAC.

AtSPL14 SBP Domain-DNA Interactions by Surface Plasmon Resonance (SPR). SPR analysis was performed using a BIAcore 2000 instrument to measure real-time interactions between DNA coupled to a sensor chip and an analyte (recombinant FBR6ss) in constant flow. A biotinlabeled 156 bp DNA containing the CCGTACA consensus binding motif identified by SELEX (clone 14, Figure 1A) was immobilized to the SA sensor chip. For controls, reference cells were either surface (no immobilized DNA) or noncognate (with a 156 bp random DNA lacking the consensus motif immobilized). The AtSPL14 SBP domainDNA interactions were then analyzed by SPR.

To determine ideal conditions for kinetic analyses, $15 \mathrm{nM}$ recombinant protein was injected at two different flow rates, 15 and $75 \mu \mathrm{L} / \mathrm{min}$. We found significant variation with flow rate, suggesting a mass transfer limitation (data not shown). Varying concentrations of recombinant protein $(5,10,15$, $20,25,30$, and $50 \mathrm{nM}$ ) were injected at the higher flow rate (75 $\mu \mathrm{L} / \mathrm{min}$ ). The SPR response data were then fit to various models using BIAevaluation 3.0 software (Biacore). Nonspecific binding was not observed when the protein concentration was less than $300 \mathrm{nM}$, and the noncognate DNA reference cell subtraction method was used (Figure S1 of the Supporting Information). The sensorgram data did not fit well to the simple bimolecular 1:1 Langmuir isotherm binding model (Figure 3A) but fit well using the binding with mass transfer model (Figure 3B). According to these data, the AtSPL14 SBP domain has extremely rapid association and dissociation rates with cognate DNA possessing the consensus binding motif; $k_{\mathrm{a}}=2.5 \times 10^{7} \mathrm{M}^{-1} \mathrm{~s}^{-1}$ and $k_{\mathrm{d}}=$ $7.4 \times 10^{-2} \mathrm{~s}^{-1}$ with equilibrium binding constant $K_{\mathrm{A}}=k_{\mathrm{a}} /$ $k_{\mathrm{d}}=3.3 \times 10^{8} \mathrm{M}^{-1}$.

Because of the mass transfer limitation, equilibrium dissociation constants were evaluated by the steady-state binding kinetics $\left(R_{\mathrm{eq}}\right)$. Nine different protein concentrations were injected at $15 \mu \mathrm{L} / \mathrm{min}$ for $10-15 \mathrm{~min}$ to ensure that the binding reaction reached equilibrium. The equilibrium binding constant $\left(K_{\mathrm{A}}\right)$ was obtained by fitting the protein concentration corresponding to the steady-state binding level 

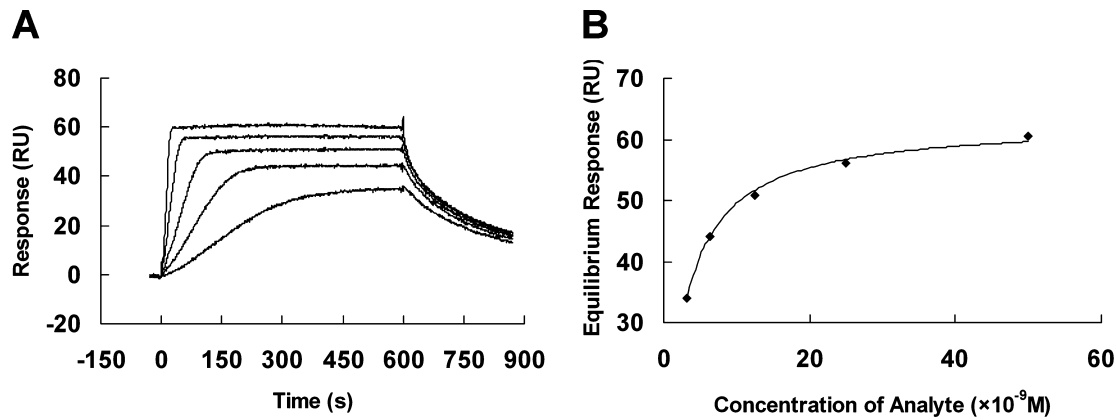

FIGURE 4: Steady-state binding affinity for the AtSPL14 SBP domain protein-DNA interaction. (A) SPR sensorgram of different concentrations of the AtSPL14 SBP domain protein $(3.125,6.25,12.5,25$, and $50 \mathrm{nM}$; bottom to top) injected onto a SA sensor chip coated with a representative 156 bp cognate dsDNA fragment identified by SELEX that bound in EMSA competition assays. Binding data were collected at a flow rate of $25 \mu \mathrm{L} / \mathrm{min}$ for $10 \mathrm{~min}$ to ensure steady-state equilibrium was reached. The response value at equilibrium $\left(R_{\mathrm{eq}}\right)$ was calculated from "fitting" straight lines to a chosen section of sensorgrams where the binding response was stabilized (steady state). (B) Plot of the response value (resonance units, RU) at equilibrium $\left(R_{\text {eq }}\right)$ versus the concentration of analyte. Data were fit to a steady-state affinity model; the equilibrium binding constant $K_{\mathrm{A}}=3.8 \times 10^{8} \mathrm{M}^{-1}$ and $\chi^{2}=0.758$.

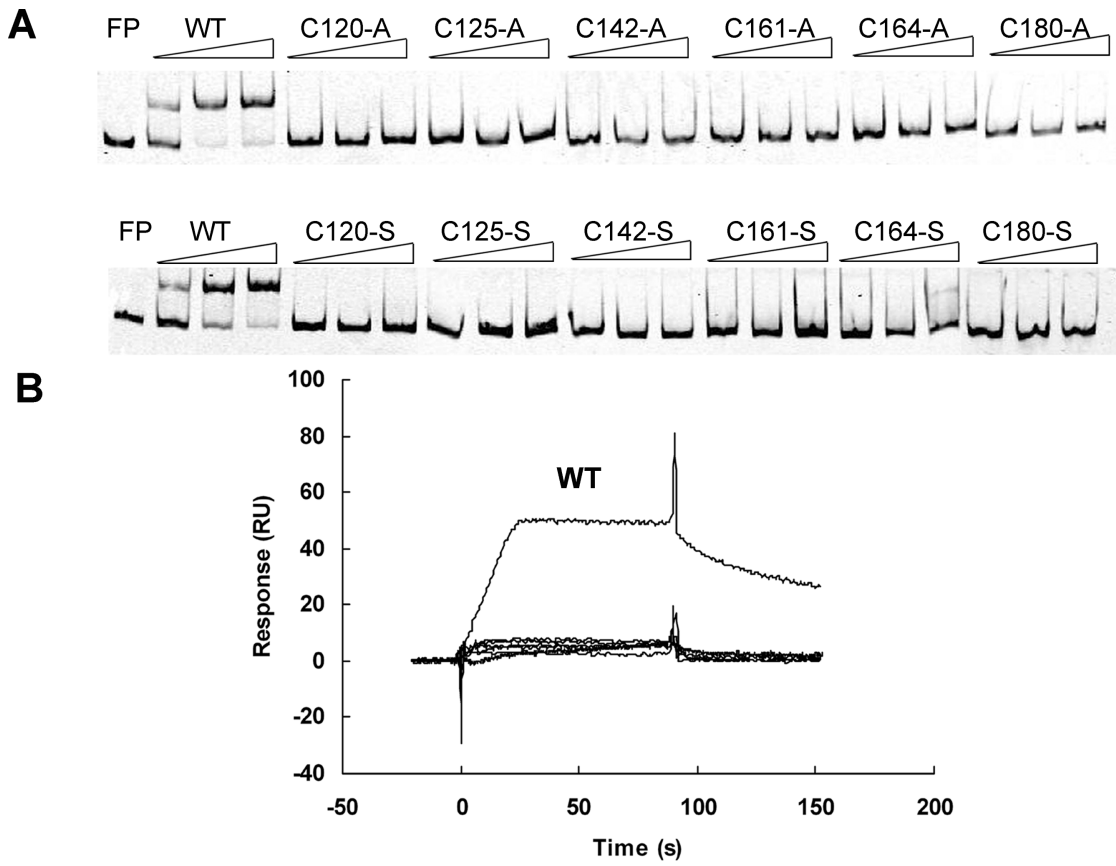

FIGURE 5: Effects of mutating the highly conserved cysteine residues in the AtSPL14 SBP domain on DNA-binding capacity. (A) The ability of wild-type (WT) and mutant (CXXX-A or CXXX-S) AtSPL14 SBP domain proteins to bind to a representative 156 bp cognate dsDNA fragment identified by SELEX was analyzed by electrophoretic mobility shift assays (EMSA). "FP" is free probe (no protein), and triangles represent increasing amounts of proteins in the binding reaction (60, 300, and $600 \mathrm{nM}$ ). (B) SPR sensorgrams showing wild-type (WT) AtSPL14 SBP domain protein binding to a cognate dsDNA immobilized on a SA sensor chip (top) compared to the SBP domain mutants (C120-A to C180-A, bottom). Binding data were collected with $50 \mathrm{nM}$ protein injected at a flow rate of $75 \mu \mathrm{L} / \mathrm{min}$ for $90 \mathrm{~s}$.

to a simple 1:1 binding model (Figure 4), resulting in an equilibrium binding constant $K_{\mathrm{A}}=3.8 \times 10^{8} \mathrm{M}^{-1}$. Experimental error was determined by performing the experiment in triplicate; $K_{\mathrm{A}}=3.1 \times 10^{8} \pm 1.0 \times 10^{8} \mathrm{M}^{-1}(\mathrm{SEM})$. Therefore, the binding affinities obtained from determining both kinetic rate constants and steady-state equilibrium analyses were similar.

Amino Acids Required for AtSPL14 SBP Domain-DNA Interactions. Multiple sequence alignments of SBP domains from A. thaliana, Antirrhinum majus, and C. reinhardtii indicate that this is a highly conserved protein domain, with sequence identity ranging from $50 \%$ to $96 \%$ (Figure S2 of the Supporting Information). The consensus sequence is $\mathrm{CX}_{4} \mathrm{C}$ $\mathrm{X}_{9} \mathrm{YX}_{3} \mathrm{HX}_{2} \mathrm{CX}_{16} \mathrm{RXCQQCX}_{3} \mathrm{HX}_{4} \mathrm{FDX}_{4} \mathrm{SCRX}_{2} \mathrm{LX}_{2} \mathrm{HNXRR}$, where " $\mathrm{X}$ " is not absolutely conserved. The six absolutely conserved Cys residues and two of the absolutely conserved His residues have been shown to coordinate two $\mathrm{Zn}^{2+}$ ions to form a novel two Zn-finger structure $(26,27)$. The presumed coordinating amino acids of the AtSPL14 SBP domain are shown in Figure S2 of the Supporting Information. To explore whether these six Cys amino acids are required for the AtSPL14 SBP domain to bind DNA, all six amino acids were individually mutated to Ala and Ser, and the mutant proteins were assayed for DNA-binding efficiency by EMSA. All 12 Cys substitutions almost completely abolished the ability of the AtSPL14 SBP domain to bind DNA, with the exception of C164-A and C164-S, which exhibited very weak binding at high protein concentrations (Figure 5). We also tested the ability of the mutant proteins to bind DNA by SPR. The binding of the mutant AtSPL14 SBP domain proteins was markedly reduced compared to the wild-type protein (Figure 5). Therefore, all six highly conserved Cys amino acids are important for DNA binding, but weak affinity is retained when one of the Cys amino 
acids predicted to coordinate a $\mathrm{Zn}^{2+}$ ion in the second $\mathrm{Zn}$ finger structure is mutated.

\section{DISCUSSION}

Our interest in determining the AtSPL14 SBP domain DNA-binding motif and binding kinetics derives from identification of an A. thaliana mutant with a disruption in the AtSPL14 gene (At1g20980). The A. thaliana FB1resistant $(f b r 6)$ mutant was originally identified by selecting for mutants capable of growth and development on media containing the fungal toxin fumonisin B1 (FB1). FB1 disrupts sphingolipid metabolism in eukaryotes (38) and induces PCD, dependent on transcription, translation, reversible protein phosphorylation, light, and hormone signaling pathways in A. thaliana $(10,11)$. In addition to resistance to FB1, the fbr6 mutant also exhibits altered plant architecture, including elongated petioles and enhanced leaf margin serration (9). Knowledge of the AtSPL14 DNA-binding site (and potentially regulated genes) is critical to fully understanding the physiological functions of this sequence-specific DNA-binding transcription factor.

The AtSPL14 SBP Domain Binds to the Core GTAC Consensus Target Site but Requires an Additional Flanking Nucleotide for Effective Interaction. AtSPL14 (At1g20980) encodes a 1035 amino acid-protein with an SBP DNAbinding domain (http://srs.ebi.ac.uk; IPR004333), a bipartite nuclear localization signal (aa 117-193), and ankyrin repeats that mediate protein-protein interactions (IPR002110; aa $821-941)$ in the C-terminal region of the protein $(9,13,39,40)$. The highly conserved SBP DNA-binding domain is a Cysand His-rich region (consensus: $\mathrm{CX}_{4} \mathrm{CX}_{13} \mathrm{HX}_{5} \mathrm{HX}_{15} \mathrm{CQQCX}_{3}-$ $\mathrm{HX}_{11} \mathrm{C}$ ) found only in proteins from photosynthetic organisms $(12,13,18,28)$. The founding members of the SBP domain gene family (SBP1 and SBP2 from A. majus) were identified by their ability to bind to the upstream regulatory region of the SQUAMOSA floral meristem identity gene (29). Previous reports indicated that A. majus proteins and some A. thaliana SBP domain proteins bind DNA encompassing a ten nucleotide motif common to cis regulatory elements in the orthologous A. majus SQUAMOSA and A. thaliana APETALA1 gene promoters and a similar motif in the $A$. majus DEFH84 promoter in vitro $(13,17)$. Alignment of these sequences revealed a putative consensus DNA-binding motif of TNCGTACAA (13). It appears that GTAC is the core DNA-binding motif for all SBP domains described so far, but nucleotides flanking the core motif are preferred by different SBP domain proteins.

We used a completely random approach, referred to as systematic evolution of ligands by exponential enrichment (SELEX) or random binding site selection (RBSS), to identify the consensus DNA-binding site for AtSPL14. These analyses revealed CCGTAC(A/G) as the optimal binding site for the AtSPL14 SBP domain (Figure 1). We found no evidence for a palindromic binding motif, which would suggest that binding occurs as a dimer, consistent with a previous report that other SBP domains bind DNA with a 1:1 stoichiometry (26). To verify the importance of the consensus motif, we mutated the individual nucleotides of the predicted binding site $\operatorname{CCGTAC}(\mathrm{A} / \mathrm{G})$ to obtain both conserved and nonconserved substitutions of each base except the $3^{\prime}$-end A/G (Figure 2B). Mutations in the CGTAC core markedly reduced competition for AtSPL14 binding, but the $\mathrm{C}$ at the $5^{\prime}$-end and the $\mathrm{A} / \mathrm{G}$ at the $3^{\prime}$-end were dispensable (Figure 2). Therefore, each individual nucleotide of the core motif CGTAC is necessary for effective AtSPL14 SBP domain DNA binding (Figure 2).

Birkenbihl et al. (28) recently used a similar random binding site selection with $\mathrm{G}$ and $\mathrm{T}$ fixed at positions 7 and 8 (of 16 total "random" nucleotides) to identify binding sites for AtSPL3 and AtSPL8 SBP domains. A high preference for at least one more $\mathrm{C}$ at the $5^{\prime}$-end of the core consensus GTAC motif was found for AtSPL3 (83\%), but not for AtSPL8. Therefore, the recognition site we determined for AtSPL14 is more similar to that of AtSPL3 than AtSPL8. The preference for a $\mathrm{C}$ flanking the GTAC core must be due to a specific amino acid-nucleotide interaction. The overall sequence identities between the AtSPL14 SBP domain and those of AtSPL3 (70\%) and AtSPL8 (74\%) are quite similar (Figure S2 of the Supporting Information), with only three amino acid differences in the $\mathrm{Zn} 2$ region proposed to interact directly with DNA (27). AtSPL14 and AtSPL3 have a Glu, Arg, and Gly whereas AtSPL8 has Asn, Lys, and Asp, respectively (Figure S2 of the Supporting Information). Whereas no simple universal code has been elucidated, specificity is imparted in most protein-DNA contacts by hydrogen bonding in the major groove (41). Statistical analysis of atomic interactions in 139 protein-DNA complexes analyzed from the Protein Data Bank (PDB) revealed favored amino acid-nucleotide pairs (42). The authors categorized direct amino acid-nucleotide contacts, including hydrogen bonds and electrostatic, hydrophobic, and other van der Waals interactions. Whereas contacts with the sugars or phosphates of DNA contribute to DNA-protein stability, only H-bonds to nucleotide bases can confer sequence specificity. In interactions with nucleotide bases, the most commonly observed interaction was Arg with G (42). Therefore, it seems most likely that the substitution of Lys in AtSPL8 for Arg in AtSPL14 and AtSPL3 renders the 5' nucleotide flanking the core GTAC motif unimportant. This hypothesis will need to be tested experimentally.

Simple pattern matching searches for the consensus binding sequence reported for the A. majus SBP proteins "TNCGTACAA" $(13,29)$ upstream of annotated A. thaliana genes identified 331 and 640 putative $S P L$-regulated genes with the pattern within 500 and 1000 base pairs of the translation start site, respectively. Using the consensus DNAbinding motif, we identified for AtSPL14 (CGTAC) more than 6000 genes with the motif within 500 base pairs of the translation start site as possible AtSPL14 targets, and one gene of unknown function has 16 occurrences. Combined with microarray gene expression data comparing the transcriptomes of the $f b r 6$ mutant to wild-type plants, a subset of candidate target genes for AtSPL14 were identified (data not shown). Whereas some of these promoter sequences also bind to AtSPL14 in vitro, additional experiments, such as chromatin immunoprecipitation (ChIP), will be required to verify that these are true targets for AtSPL14 in vivo.

The Kinetic Binding Parameters of SBP Domains Differ. The SBP domain DNA binding is dependent on the presence of $\mathrm{Zn}^{2+}$ ions $(18,28)$. The NMR-resolved structures of SBP domains revealed that the SBP domain forms a novel two $\mathrm{Zn}$ structure DNA-binding domain (26). The two $\mathrm{Zn}^{2+}$ ions are coordinated by three Cys residues and one His residue, 
forming two $\mathrm{Zn}$ structures in $\mathrm{CCCH}$ (Zn1) and $\mathrm{CCHC}(\mathrm{Zn} 2)$ configurations (Figure S2 of the Supporting Information). We mutated all six highly conserved Cys to Ala and Ser and determined the SBP-DNA binding efficiency by EMSA and SPR. All 12 mutations markedly reduced the AtSPL14DNA interaction (Figure 2), verifying that all six conserved Cys in the AtSPL14 SBP DNA-binding domain are important for AtSPL14 protein-DNA interaction and consistent with the supposition that these Cys residues participate in $\mathrm{Zn}^{2+}$ ion binding $(26,28)$. However, the C164-A and C164-S (corresponding to the second Cys in Zn2) mutant proteins retained some weak binding ability (Figures 2 and S2 of the Supporting Information). The second Cys and the His in $\mathrm{Zn} 1$ and the first and fourth Cys in Zn2 were reported to be critical for AtSPL1 DNA binding (28). In that study the second Cys in $\mathrm{Zn} 2$ was not mutated, but the His in $\mathrm{Zn} 2$ was found to be somewhat dispensable (28). Therefore, we independently determined that all of the $\mathrm{Zn} 1$ coordinating residues are essential, but two of the presumed $\mathrm{Zn} 2$ coordinating residues (the His and second Cys) are not absolutely required for SBP domain DNA binding. These findings support the conclusions derived from the NMR structure of a truncated SBP domain protein (AtSPL12). The Zn1 structure is critical for overall structure, and removal of part of the Zn2 domain affected DNA binding but had little effect on overall folding (27). It is not yet clear whether proteins with mutations of the $\mathrm{Zn}^{2+}$ ion coordinating amino acids (His and second Cys) in the $\mathrm{Zn} 2$ structure can still bind a second $\mathrm{Zn}^{2+}$ ion. Another His residue is absolutely conserved in SBP domains (His 187 in AtSPL14, Figure S2 of the Supporting Information) and might serve as a substitute fourth ligand. Alternatively, acidic residues or a water molecule might serve as the fourth coordinating ligand (43).

The AtSPL14 DNA-binding kinetics was analyzed by surface plasmon resonance (SPR). The mass transfer limitation due to the rapid association $\left(>10^{7}\right)$ and dissociation rates $\left(>10^{-2}\right)$ made determination of reliable kinetic constants difficult using conventional SPR (32). Therefore, we also evaluated steady-state binding at equilibrium. The determined equilibrium binding constant, $K_{\mathrm{A}}\left(3.8 \times 10^{8} \mathrm{M}^{-1}\right)$, is similar to the reported values $\left(9.6 \times 10^{7} \mathrm{M}^{-1}\right.$ and $\left.>5 \times 10^{8} \mathrm{M}^{-1}\right)$ for the AtSPL4 and AtSPL12 SBP domains, respectively, and 1 order of magnitude greater than the value $\left(2.8 \times 10^{7}\right.$ $\mathrm{M}^{-1}$ ) reported for the AtSPL7 SBP domain $(26,27)$. Kinetic rate constants were not reported for other SBP domain proteins.

The different $K_{\mathrm{A}}$ values determined for different SBP domains might be due to the different salt concentrations in the analyte. Our data were generated in HBS-EP buffer (containing $150 \mathrm{mM} \mathrm{NaCl}$ ), whereas the $K_{\mathrm{A}}$ of binding for AtSPL4, AtSPL7, and AtSPL12 was assayed in the presence of 100 or $300 \mathrm{mM} \mathrm{KCl}$. The $K_{\mathrm{A}}$ for AtSPL12 and AtSPL4 at $100 \mathrm{mM} \mathrm{KCl}\left(>5 \times 10^{8} \mathrm{M}^{-1}\right.$ and $2.8 \times 10^{7} \mathrm{M}^{-1}$, respectively) was higher than those determined at $300 \mathrm{mM}$ $\mathrm{KCl}\left(3.2 \times 10^{7} \mathrm{M}^{-1}\right.$ and $2.1 \times 10^{6} \mathrm{M}^{-1}$, respectively), suggesting that salt concentration affects SBP domain-DNAbinding affinity. Therefore, electrostatic forces contribute to the SBP-DNA interaction, as was also observed in other protein-DNA interactions $(44,45)$.

Conclusions. In summary, different SBP domain proteins display different binding affinities to the same DNA and different selectivity for DNA targets. Even though they contain the same core consensus binding motif (GTAC), the A. thaliana APETALAl gene-derived DNA and DNA containing the $C$. reinhardtii copper-responsive element (CuRE) had different affinities for several SBP domain proteins (28). Our results revealed that AtSPL14-DNA binding is highly sequence selective and allow us to hypothesize which particular amino acids may confer that specificity. Moreover, the well-conserved SBP domains possess diverse DNAbinding affinities for similar DNA sequences. These observations will be useful, in conjunction with additional experimentation, to identify the gene targets for individual SBP domain family members to understand their physiological functions in the context of whole organisms.

\section{ACKNOWLEDGMENT}

We thank Weimin Zhang for technical assistance with the SPR experiments, Michael Fromm, Director of the University of Nebraska-Lincoln Center for Biotechnology, for access to the Biacore 2000 and funding for Biacore training, Dmitri Fomenko for help with the MEME analyses, and other members of the Stone laboratory for useful discussions.

\section{SUPPORTING INFORMATION AVAILABLE}

SPR data analysis comparing the subtraction of the signals from a blank reference cell and a reference cell coated with a noncognate DNA indicates that subtracting data from a reference cell coated with noncognate DNA is the preferred control (Figure S1). An amino acid alignment of the SBP DNA-binding domains encoded by the $16 \mathrm{~A}$. thaliana genes, the 2 A. majus genes, and the CuRE-binding C. reinhardtii gene is provided with a schematic of the $\mathrm{Zn}^{2+}$ ion coordinating residues (Figure S2). The oligonucleotide primers used for site-directed mutagenesis of both the DNA target and the AtSPL14 SBP domain protein are shown in supplementary tables (Tables S1 and S2). This material is available free of charge via the Internet at http://pubs.acs.org.

\section{REFERENCES}

1. Deyhle, F., Sarkar, A. K., Tucker, E. J., and Laux, T. (2007) WUSCHEL regulates cell differentiation during anther development. Dev. Biol. 302, 154-159.

2. van Doorn, W. G., and Woltering, E. J. (2005) Many ways to exit? Cell death categories in plants. Trends Plant Sci. 10, 117-122.

3. Groover, A., and Jones, A. M. (1999) Tracheary element differentiation uses a novel mechanism coordinating programmed cell death and secondary cell wall synthesis. Plant Physiol. 119, 375384.

4. Demura, T., Tashiro, G., Horiguchi, G., Kishimoto, N., Kubo, M., Matsuoka, N., Minami, A., Nagata-Hiwatashi, M., Nakamura, K., Okamura, Y., Sassa, N., Suzuki, S., Yazaki, J., Kikuchi, S., and Fukuda, H. (2002) Visualization by comprehensive microarray analysis of gene expression programs during transdifferentiation of mesophyll cells into xylem cells. Proc. Natl. Acad. Sci. U.S.A. 99, 15794-15799.

5. Fukuda, H. (2000) Programmed cell death of tracheary elements as a paradigm in plants. Plant Mol. Biol. 44, 245-253.

6. Gechev, T. S., Van Breusegem, F., Stone, J. M., Denev, I., and Laloi, C. (2006) Reactive oxygen species as signals that modulate plant stress responses and programmed cell death. BioEssays 28 , 1091-1101.

7. Gilchrist, D. G. (1998) Programmed cell death in plant disease: the purpose and promise of cellular suicide. Annu. Rev. Phytopathol. 36, 393-414.

8. Beers, E. P., and McDowell, J. M. (2001) Regulation and execution of programmed cell death in response to pathogens, stress and developmental cues. Curr. Opin. Plant Biol. 4, 561-567. 
9. Stone, J. M., Liang, X., Nekl, E. R., and Stiers, J. J. (2005) Arabidopsis AtSPL14, a plant-specific SBP-domain transcription factor, participates in plant development and sensitivity to fumonisin B1. Plant J. 41, 744-754.

10. Stone, J. M., Heard, J. E., Asai, T., and Ausubel, F. M. (2000) Simulation of fungal-mediated cell death by fumonisin B1 and selection of fumonisin B1-resistant (fbr) Arabidopsis mutants. Plant Cell 12, 1811-1822.

11. Asai, T., Stone, J. M., Heard, J. E., Kovtun, Y., Yorgey, P., Sheen, J., and Ausubel, F. M. (2000) Fumonisin B1-induced cell death in Arabidopsis protoplasts requires jasmonate-, ethylene-, and salicylate-dependent signaling pathways. Plant Cell 12, 1823-1836.

12. Xie, K., Wu, C., and Xiong, L. (2006) Genomic organization, differential expression and interaction of SQUAMOSA promoterbinding-like transcription factors and microRNA156 in rice. Plant Physiol. 142, 280-293.

13. Cardon, G., Hohmann, S., Klein, J., Nettesheim, K., Saedler, H., and Huijser, P. (1999) Molecular characterisation of the Arabidopsis SBP-box genes. Gene 237, 91-104.

14. Moreno, M. A., Harper, L. C., Krueger, R. W., Dellaporta, S. L., and Freeling, M. (1997) liguleless1 encodes a nuclear-localized protein required for induction of ligules and auricles during maize leaf organogenesis. Genes Dev. 11, 616-628.

15. Wang, H., Nussbaum-Wagler, T., Li, B., Zhao, Q., Vigouroux, Y., Faller, M., Bomblies, K., Lukens, L., and Doebley, J. F. (2005) The origin of the naked grains of maize. Nature 436, 714-719.

16. Unte, U. S., Sorensen, A. M., Pesaresi, P., Gandikota, M., Leister, D., Saedler, H., and Huijser, P. (2003) SPL8, an SBP-box gene that affects pollen sac development in Arabidopsis. Plant Cell 15, 1009-1019.

17. Cardon, G. H., Hohmann, S., Nettesheim, K., Saedler, H., and Huijser, P. (1997) Functional analysis of the Arabidopsis thaliana SBP-box gene SPL3: a novel gene involved in the floral transition. Plant J. 12, 367-377.

18. Kropat, J., Tottey, S., Birkenbihl, R. P., Depege, N., Huijser, P., and Merchant, S. (2005) A regulator of nutritional copper signaling in Chlamydomonas is an SBP domain protein that recognizes the GTAC core of copper response element. Proc. Natl. Acad. Sci. U.S.A. 102, 18730-18735.

19. Merchant, S. S., Allen, M. D., Kropat, J., Moseley, J. L., Long, J. C., Tottey, S., and Terauchi, A. M. (2006) Between a rock and a hard place: trace element nutrition in Chlamydomonas. Biochim. Biophys. Acta 1763, 578-594.

20. Zhang, Y., Schwarz, S., Saedler, H., and Huijser, P. (2007) SPL8, a local regulator in a subset of gibberellin-mediated developmental processes in Arabidopsis. Plant Mol. Biol. 63, 429-439.

21. Manning, K., Tor, M., Poole, M., Hong, Y., Thompson, A. J., King, G. J., Giovannoni, J. J., and Seymour, G. B. (2006) A naturally occurring epigenetic mutation in a gene encoding an SBP-box transcription factor inhibits tomato fruit ripening. Nat. Genet. 38, 948-952.

22. Lee, J., Park, J. J., Kim, S. L., Yim, J., and An, G. (2007) Mutations in the rice liguleless gene result in a complete loss of the auricle, ligule, and laminar joint. Plant Mol. Biol. 65, 487-499.

23. Jones-Rhoades, M. W., and Bartel, D. P. (2004) Computational identification of plant microRNAs and their targets, including a stress-induced miRNA. Mol. Cell 14, 787-799.

24. Xie, Z., Allen, E., Fahlgren, N., Calamar, A., Givan, S. A., and Carrington, J. C. (2005) Expression of Arabidopsis MIRNA genes. Plant Physiol. 138, 2145-2154.

25. Gandikota, M., Birkenbihl, R. P., Hohmann, S., Cardon, G. H., Saedler, H., and Huijser, P. (2007) The miRNA156/157 recognition element in the 3' UTR of the Arabidopsis SBP box gene SPL3 prevents early flowering by translational inhibition in seedlings. Plant J. 49, 683-693.

26. Yamasaki, K., Kigawa, T., Inoue, M., Tateno, M., Yamasaki, T., Yabuki, T., Aoki, M., Seki, E., Matsuda, T., Nunokawa, E., Ishizuka, Y., Terada, T., Shirouzu, M., Osanai, T., Tanaka, A., Seki, M., Shinozaki, K., and Yokoyama, S. (2004) A novel zincbinding motif revealed by solution structures of DNA-binding domains of Arabidopsis SBP-family transcription factors. J. Mol. Biol. 337, 49-63.
27. Yamasaki, K., Kigawa, T., Inoue, M., Yamasaki, T., Yabuki, T., Aoki, M., Seki, E., Matsuda, T., Tomo, Y., Terada, T., Shirouzu, M., Tanaka, A., Seki, M., Shinozaki, K., and Yokoyama, S. (2006) An Arabidopsis SBP-domain fragment with a disrupted C-terminal zinc-binding site retains its tertiary structure. FEBS Lett. 580, 21092116.

28. Birkenbihl, R. P., Jach, G., Saedler, H., and Huijser, P. (2005) Functional dissection of the plant-specific SBP-domain: overlap of the DNA-binding and nuclear localization domains. J. Mol. Biol. $352,585-596$.

29. Klein, J., Saedler, H., and Huijser, P. (1996) A new family of DNA binding proteins includes putative transcriptional regulators of the Antirrhinum majus floral meristem identity gene SQUAMOSA. Mol. Gen. Genet. 250, 7-16.

30. Sambrook, J., and Russell, D. W. (2001) Molecular cloning: a laboratory manual, 3rd ed., Cold Spring Harbor Laboratory Press, Cold Spring Harbor, NY.

31. Watson, D. K., Kitching, R., Vary, C., Kola, I., and Seth, A. (2000) Isolation of target gene promoter/enhancer sequences by whole genome PCR method, in Transcription Factor Protocols (Tymms, M. J., Ed.) pp 1-11, Humana Press, Totowa, NJ.

32. Karlsson, R. (1999) Affinity analysis of non-steady-state data obtained under mass transport limited conditions using BIAcore technology. J. Mol. Recognit. 12, 285-292.

33. Kalifa, Y., Gilad, A., Konrad, Z., Zaccai, M., Scolnik, P. A., and Bar-Zvi, D. (2004) The water- and salt-stress-regulated Asrl (abscisic acid stress ripening) gene encodes a zinc-dependent DNAbinding protein. Biochem. J. 381, 373-378.

34. Manuel, M., Rallu, M., Loones, M. T., Zimarino, V., Mezger, V., and Morange, M. (2002) Determination of the consensus binding sequence for the purified embryonic heat shock factor 2. Eur. J. Biochem. 269, 2527-2537.

35. Ausubel, F. M., Brent, R., Kingston, R. E., Moore, D. D., Seidman, J. G., Smith, J. A., and Struhl, K., Eds. (2006) Current Protocols in Molecular Biology, John Wiley and Sons, New York, NY.

36. Grundy, W. N., Bailey, T. L., Elkan, C. P., and Baker, M. E. (1997) Meta-MEME: motif-based hidden Markov models of protein families. Comput. Appl. Biosci. 13, 397-406.

37. Crooks, G. E., Hon, G., Chandonia, J. M., and Brenner, S. E. (2004) WebLogo: a sequence logo generator. Genome Res. 14, 1188-1190.

38. Desai, K., Sullards, M. C., Allegood, J., Wang, E., Schmelz, E. M., Hartl, M., Humpf, H. U., Liotta, D. C., Peng, Q., and Merrill, A. H., Jr. (2002) Fumonisins and fumonisin analogs as inhibitors of ceramide synthase and inducers of apoptosis. Biochim. Biophys. Acta 1585, 188-192.

39. Chen, L. (1999) Combinatorial gene regulation by eukaryotic transcription factors. Curr. Opin. Struct. Biol. 9, 48-55.

40. Robbins, J., Dilworth, S. M., Laskey, R. A., and Dingwall, C. (1991) Two interdependent basic domains in nucleoplasmin nuclear targeting sequence: identification of a class of bipartite nuclear targeting sequence. Cell 64, 615-623.

41. Luscombe, N. M., Laskowski, R. A., and Thornton, J. M. (2001) Amino acid-base interactions: a three-dimensional analysis of protein-DNA interactions at an atomic level. Nucleic Acids Res. 29, 2860-2874.

42. Lejeune, D., Delsaux, N., Charloteaux, B., Thomas, A., and Brasseur, R. (2005) Protein-nucleic acid recognition: statistical analysis of atomic interactions and influence of DNA structure. Proteins 61, 258-271.

43. Kornhaber, G. J., Snyder, D., Moseley, H. N., and Montelione, G. T. (2006) Identification of zinc-ligated cysteine residues based on ${ }^{13} \mathrm{C} \alpha$ and ${ }^{13} \mathrm{C} \beta$ chemical shift data. J. Biomol. NMR 34, 259269.

44. Seimiya, M., and Kurosawa, Y. (1996) Kinetics of binding of Antp homeodomain to DNA analyzed by measurements of surface plasmon resonance. FEBS Lett. 398, 279-284.

45. Oda, M., Furukawa, K., Sarai, A., and Nakamura, H. (1999) Kinetic analysis of DNA binding by the c-Myb DNA-binding domain using surface plasmon resonance. FEBS Lett. 454, 288-292.

BI701431Y 
FIGURE S1: Comparison of surface and noncognate dsDNA-coated reference cell subtraction methods. SPR sensorgrams of different concentrations of the AtSPL14-SBP domain protein (3.125, 6.25, 12.5, 25, 50, 100, 200 and $300 \mathrm{nM}$; bottom to top) injected onto a SA sensor chip coated with a representative 156 bp cognate dsDNA fragment identified by SELEX that bound in EMSA competition assays. Binding data were collected at a flow rate of $25 \mu \mathrm{L} / \mathrm{min}$. A) Sensorgram with signals from the control surface reference cell (no DNA) subtracted. B) Sensorgram with signals from the control reference cell (coated with a noncognate dsDNA) subtracted.

FIGURE S2: Multiple sequence alignment of several SBP DNA-binding domains and $\mathrm{Zn}^{2+}$ ion coordination. A) SBP domain sequences were aligned using the Clustal method with DNAStar software (Madison, WI). Residues that match the consensus sequence are shaded in black, numbers on the left refer to the starting amino acid, protein designations are indicated on the right (organisms: At, Arabidopsis thaliana; Cr, Chlamydomonas reinhardtii; and Am, Antirrhinum majus), and asterisks and amino acid numbers indicate the positions of the six highly conserved cysteines that were mutated in the AtSPL14 SBP domain. B) The coordinating Cys and His residues for $\mathrm{Zn}^{2+}$ ions are indicated for the $\mathrm{Zn} 1$ (CCCH) and $\mathrm{Zn} 2$ (CCHC) structures. 

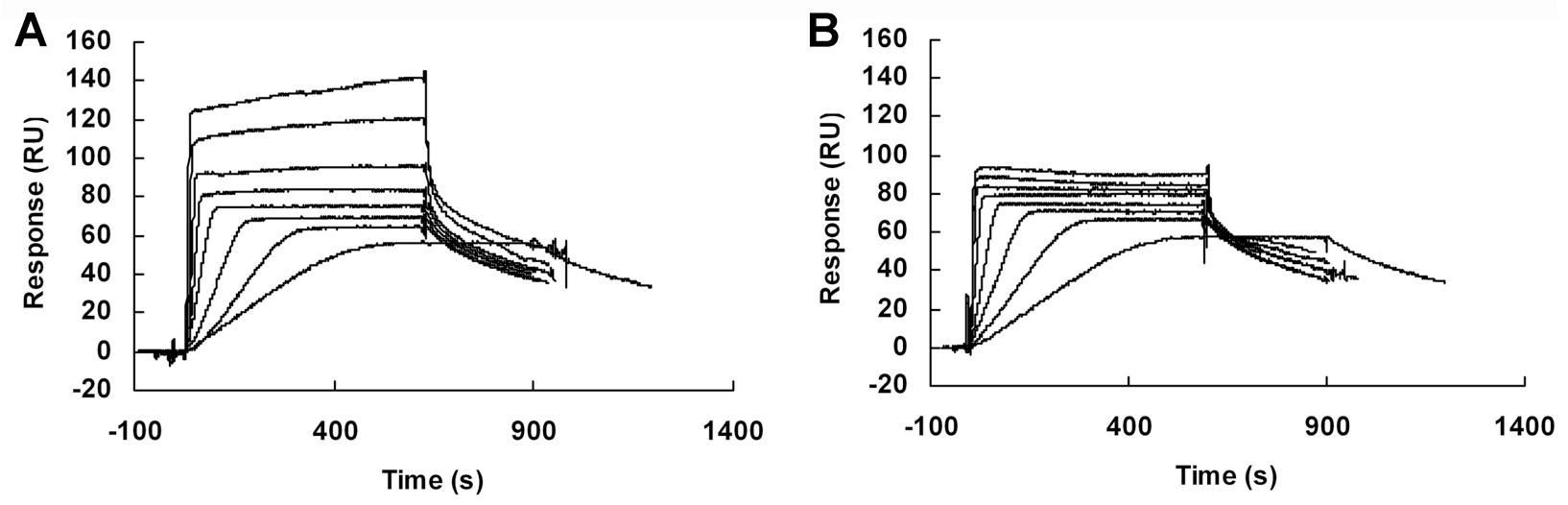
A

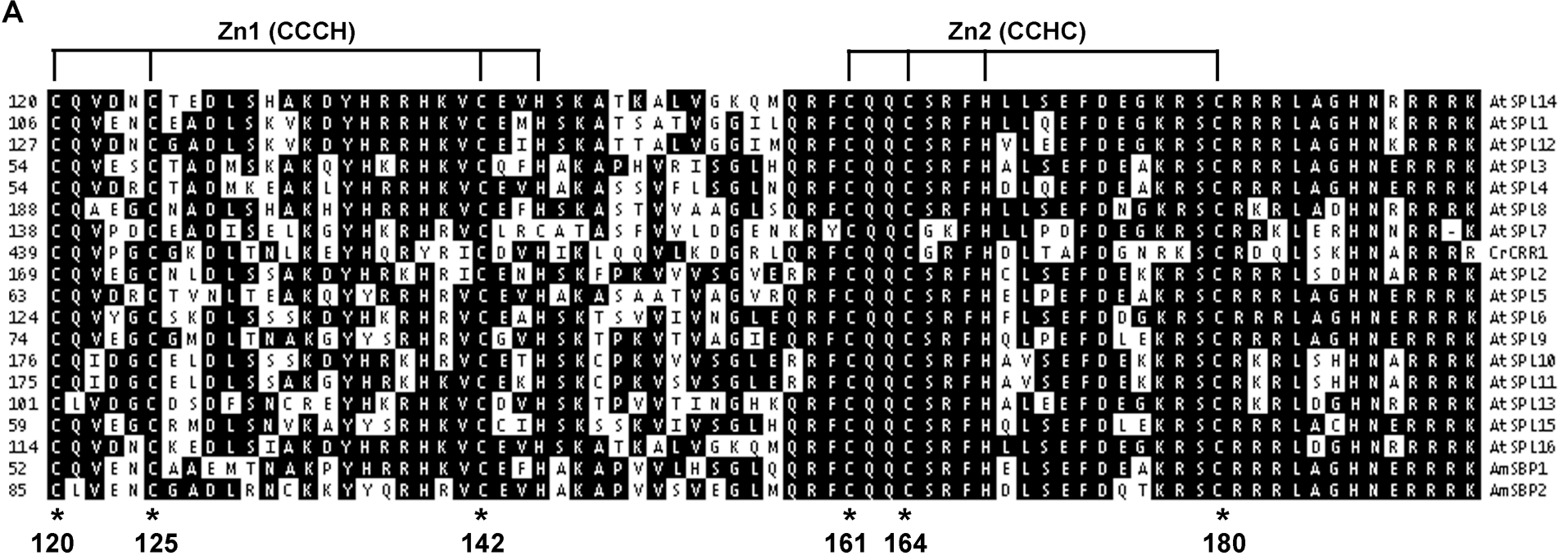

B

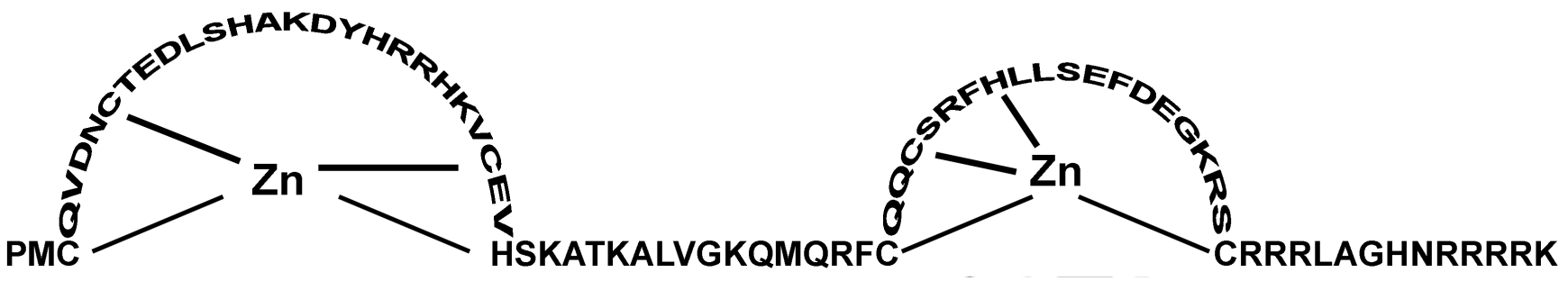


Table S1. Oligonucleotide primers used for site-directed mutagenesis of SELEX binders

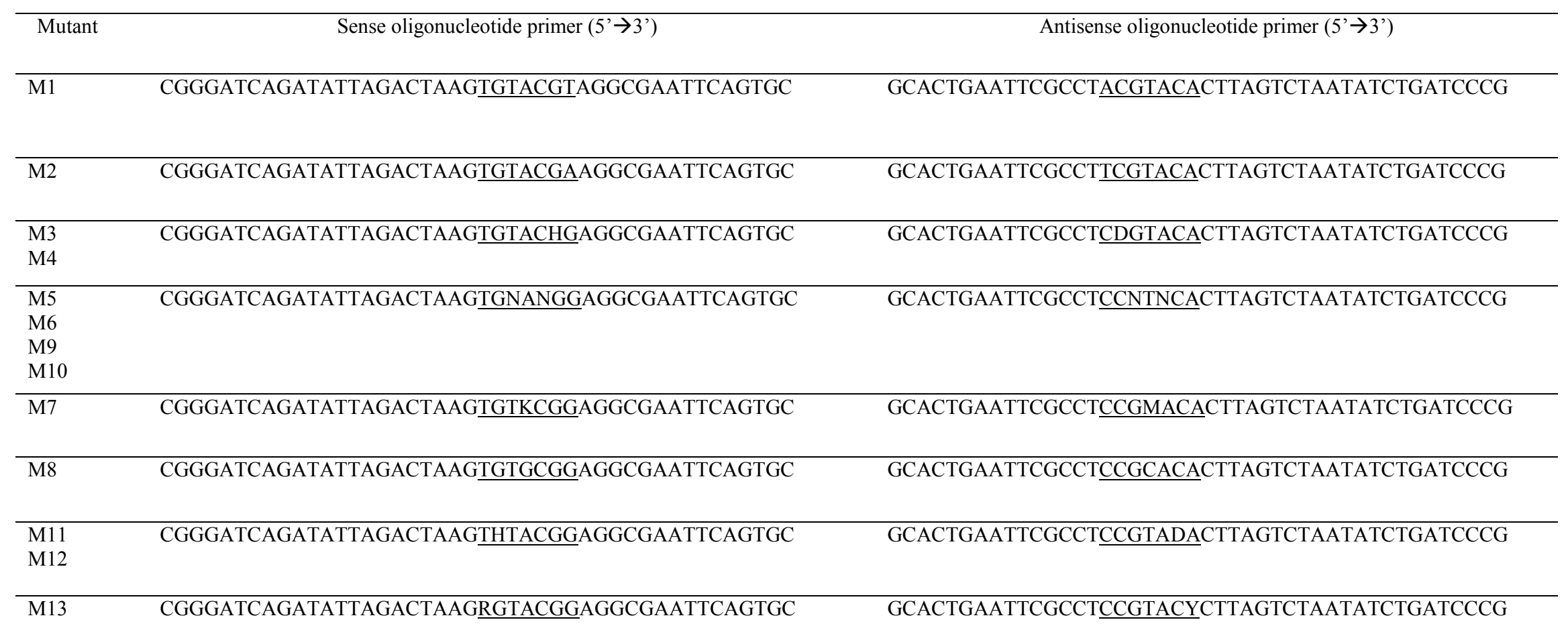

Note: $\mathrm{D}=\mathrm{A}, \mathrm{G}, \mathrm{T} ; \mathrm{H}=\mathrm{A}, \mathrm{C}, \mathrm{T} ; \mathrm{K}=\mathrm{G}, \mathrm{T} ; \mathrm{M}=\mathrm{A}, \mathrm{C} ; \mathrm{N}=\mathrm{A}, \mathrm{C}, \mathrm{G}, \mathrm{T} ; \mathrm{R}=\mathrm{A}, \mathrm{G} ; \mathrm{Y}=\mathrm{C}, \mathrm{T}$ 
Table S2. Oligonucleotide primers used for site-directed mutagenesis of AtSPL14 SBP domain

\begin{tabular}{|c|c|c|}
\hline Mutant & Sense oligonucleotide primer $\left(5^{\prime} \rightarrow 3^{\prime}\right)$ & Antisense oligonucleotide primer $\left(5^{\prime} \rightarrow 3^{\prime}\right)$ \\
\hline $\mathrm{C} 120 \mathrm{~A}$ & CCGGGAGGGAATTATCCCATGGCTCAGGTTGATAATTG & CAATTATCAACCTGAGCCATGGGATAATTCCCTCCCGG \\
\hline $\mathrm{C} 125 \mathrm{~A}$ & CCCATGTGTCAGGTTGATAATGCTACTGAAGATTTGTCTCATGC & GCATGAGACAAATCTTCAGTAGCATTATCAACCTGACACATGGG \\
\hline $\mathrm{C} 142 \mathrm{~A}$ & CATAGAAGGCATAAAGTTGCTGAAGTTCATAGTAAAGCTA & GTAGCTTTACTATGAACTTCAGCAACTTTATGCCTTCTATG \\
\hline C161A & GGTAAACAGATGCAGAGGTTTGCTCAACAGTGTAGCAGG & CCTGCTACACTGTTGAGCAAACCTCTGCATCTGTTTACC \\
\hline $\mathrm{C} 164 \mathrm{~A}$ & CAGATGCAGAGGTTTTGCCAACAGGCTAGCAGGTTTCATCTGC & GCAGATGAAACCTGCTAGCCTGTTGGCAAAACCTCTGCATCTG \\
\hline $\mathrm{C} 180 \mathrm{~A}$ & GAGGGGAAGAGAAGTGCTAGGCGTAGATTGGCTGG & CCAGCCAATCTACGCCTAGCACTTCTCTTCCCCTC \\
\hline C120S & CCGGGAGGGAATTATCCCATGTCTCAGGTTGATAATTG & CAATTATCAACCTGAGACATGGGATAATTCCCTCCCGG \\
\hline $\mathrm{C} 125 \mathrm{~S}$ & CCCATGTGTCAGGTTGATAATTCTACTGAAGATTTGTCTCATGC & GCATGAGACAAATCTTCAGTAGAATTATCAACCTGACACATGGG \\
\hline C142S & CATAGAAGGCATAAAGTTTCTGAAGTTCATAGTAAAGCTAC & GTAGCTTTACTATGAACTTCAGAAACTTTATGCCTTCTATG \\
\hline C161S & GGTAAACAGATGCAGAGGTTTTCTCAACAGTGTAGCAG & CCTGCTACACTGTTGAGAAAACCTCTGCATCTGTTTACC \\
\hline C164S & CAGATGCAGAGGTTTTGCCAACAGTCTAGCAGGTTTCATCTGC & GCAGATGAAACCTGCTAGACTGTTGGCAAAACCTCTGCATCTG \\
\hline C180S & GAGGGGAAGAGAAGTTCGAGGCGTAGATTGGCTGG & CCAGCCAATCTACGCCTCGAACTTCTCTTCCCCTC \\
\hline
\end{tabular}

